Article

\title{
Optimal Planning of Integrated Nuclear-Renewable Energy System for Marine Ships Using Artificial Intelligence Algorithm
}

\author{
Hossam A. Gabbar ${ }^{1,2, *(D)}$, Md. Ibrahim Adham ${ }^{1}$ (D) and Muhammad R. Abdussami ${ }^{1}$ (D) \\ 1 Faculty of Energy Systems and Nuclear Science, Ontario Tech University (UOIT), \\ Oshawa, ON L1G 0C5, Canada; mdibrahim.adham@ontariotechu.net (M.I.A.); mdrafiul.abdussami@uoit.net \\ or mdrafiul.abdussami@ontariotechu.net (M.R.A.) \\ 2 Faculty of Engineering and Applied Science, Ontario Tech University (UOIT), Oshawa, ON L1G 0C5, Canada \\ * Correspondence: hossam.gaber@uoit.ca
}

check for updates

Citation: Gabbar, H.A.; Adham, M.I.; Abdussami, M.R. Optimal Planning of Integrated Nuclear-Renewable Energy System for Marine Ships Using Artificial Intelligence Algorithm. Energies 2021, 14, 3188. https://doi.org/10.3390/ en14113188

Academic Editors: John C. Wagner and Steven E. Aumeier

Received: 19 April 2021

Accepted: 25 May 2021

Published: 29 May 2021

Publisher's Note: MDPI stays neutral with regard to jurisdictional claims in published maps and institutional affiliations.

Copyright: (c) 2021 by the authors. Licensee MDPI, Basel, Switzerland. This article is an open access article distributed under the terms and conditions of the Creative Commons Attribution (CC BY) license (https:/ / creativecommons.org/licenses/by/ $4.0 /)$.

\begin{abstract}
Ocean-going ships are one of the primary sources of Greenhouse Gas (GHG) emissions. Several actions are being taken to reduce the GHG emissions from maritime vessels, and integration of Renewable Energy Sources (RESs) is one of them. Ocean-going marine ships need a large amount of reliable energy to support the propulsive load. Intermittency is one of the drawbacks of RESs, and penetration of RESs in maritime vessels is limited by the cargo carrying capacity and usable area of that ship. Other types of reliable energy sources need to be incorporated in ships to overcome these shortcomings of RESs. Some researchers proposed to integrate fossil fuel-based generators like diesel generators and renewable energy in marine vessels to reduce GHG emissions. As the penetration of RESs in marine ships is limited, fossil fuel-based generators provide most of the energy. Therefore, renewable and fossil fuel-based hybrid energy systems in maritime vessels can not reduce GHG emissions to the desired level. Fossil fuel-based generators need to be replaced by emissions-free energy sources to make marine ships free from emissions. Nuclear energy is emissions-free energy, and small-scale nuclear reactors like Microreactors (MRs) are competent to replace fossil fuel-based generators. In this paper, the technical, environmental, and economic competitiveness of NuclearRenewable Hybrid Energy Systems (N-R HES) in marine ships are assessed. The lifecycle cost of $M R$, reliability of the proposed system, and limitations of integrating renewable energy in maritime vessels are considered in this study. The proposed N-R HES is compared with three different energy systems, namely 'Standalone Fossil Fuel-based Energy Systems', 'Renewable and Fossil Fuel-based Hybrid Energy Systems', and 'Standalone Nuclear Energy System'. The cost modeling of each energy system is carried out in MATLAB simulator. Each energy system is optimized by using the Differential Evolution Algorithm (DEA), an artificial intelligence algorithm, to find out the optimal configuration of the system components in terms of Net Present Cost (NPC). The results determine that N-R HES has the lowest NPC compared to the other three energy systems. The performance of the DE algorithm is compared with another widely accepted artificial intelligence optimization technique called 'Particle Swarm Optimization (PSO)' to validate the findings of the $\mathrm{DE}$ algorithm. The impact of control parameters in the DE algorithm is assessed by employing the Adaptive Differential Evolution (ADE) algorithm. A sensitivity analysis is carried out to assess the impact of different system parameters on this study's findings.
\end{abstract}

Keywords: Microreactors; renewable energy; hybrid energy systems; ships; lifecycle cost; economic assessment; Differential Evolution (DE); sensitivity analysis

\section{Introduction}

If global shipping were a country, it would be considered as the sixth-largest producer of $\mathrm{CO}_{2}$ after the United States, China, Russia, India, and Japan. Ocean-going shipping is responsible for more than $3 \%$ of global $\mathrm{CO}_{2}$ emissions [1]. Although international shipping is not a part of the Paris Agreement, the International Maritime Organization (IMO) is 
focusing on a strategy to reduce the GHG emissions from ships. They set a phase-wise target and emphasize technical, operational, and innovative solutions to lessen GHG emissions. It is the responsibility of the IMO to regulate the world shipping sector. To date, there is only one regulation to improve the ship's energy efficiency related to new ship design: the Energy Efficiency Design Index (EEDI). The target of this regulation is to improve ship efficiency by $10 \%, 20 \%$, and 30\% within 2019, 2024, and 2025 or after, respectively. As the regulation is related to the new ship only, clearly it cannot reduce the GHG emissions effectively. However, IMO is developing strategies to reduce GHG emissions from maritime vessels. The initial strategy has been delivered in 2018, and the comprehensive strategy will be available within 2023. IMO strategy will include short, mid, and long-term actions to reduce the GHG emissions from marine transportation. In the short-term measure, it includes limiting the ship speed as the power requirement of the main engine is proportional to the cube of the speed. It has been found that reducing ship speed is a cost-effective option to lower GHG emissions [2]. In the mid and long-term initiatives, the main focus is on new marine technologies and low and zero-carbon fuels. The Institute of Marine Engineering, Science and Technology (IMarEST) and the Royal Institution of Naval Architects (RINA) suggest that with the help of existing technology, GHG emissions can be reduced $7.5 \%$ to $19.4 \%$. However, for a large amount of GHG emissions reduction, zero or low-carbon fuels are needed.

Natural gas is a potential candidate that can be used in marine vessels. Natural gas has some limitations like limited availability due to higher land-based demand and lower density of volumetric energy. Also, natural gas requires a higher area for storage compared to fossil fuel. The fuel cell is another potential candidate to solve the emissions problem from marine ships. However, due to lower availability and lower volumetric energy density, the fuel cell is not a feasible option. Also, the fuel cells employ natural gas or traditional fossil fuel which will make the system more complex and will not solve the emissions problem. Battery electric propulsion could be used to reduce GHG emissions from maritime vessels. Although battery is promising in the marine industry, mass using of the battery will have some environmental impact as it requires metals, non-metals, and rare earth material which generate environmental pollutants. The negative impact of large-scale battery usage will significantly change the implementation of batteries in the marine sector [3].

Renewable energy sources could be the possible solutions to reduce GHG emissions. The potential renewable energy sources for marine ships are wind energy, solar energy, biofuels, and wave energy. The wind energy can be used as soft sails, rotors, fixed wings, kites, and conventional wind turbines. The marine ships may need to be retrofitted to integrate the renewable energy sources or design accordingly during the shipbuilding phase. Nevertheless, due to the intermittency of renewable energy sources, it is not suitable for standalone marine propulsion, and more preferable for auxiliary propulsion [4]. To avoid the intermittency of renewable energy sources, energy storage systems can be employed. Unlike, land-based energy systems, there are limitations on installing renewable energy and energy storage systems in maritime vessels. In marine ships, the area for implementing renewable energy (solar PV and wind turbine) sources and energy storage systems is limited and the weight of the renewable energy sources and energy storage systems need to be within a boundary to ensure the cargo carrying capacity is not affected by the weight of energy systems [5]. Hence, the contribution of renewable energy in marine ships will be limited even in optimistic scenarios. However, with the help of energy storage feature, marine ship can act as prosumer in nodal models of energy while loading and unloading cargo in ports [6]. As the contribution of renewable energy is limited, most of the energy will be served by the diesel engine. Hence, the integration of renewable energy with fossil-fuel-based energy systems is not a feasible option to reduce GHG emissions to the desired level. To make the marine vessels free from emissions, fossil fuel-based energy systems need to be replaced by emissions-free energy systems. Nuclear energy is free from emissions during operation although there are some pollutants emit during the 
mining, milling, transportation, plant construction, and decommissioning stage. As per IMarEST reports, nuclear power the only option which is emission-free and can replace fossil fuels [7]. Hence, small-scale nuclear reactor: microreactor (MR) could be a suitable candidate to replace the fossil fuel-based energy systems from marine transportation.

To the authors' best knowledge, no study has been carried out on the integration of nuclear-renewable energy in marine ships. Although several studies are being carried out for land-based N-RHES, the marine sector is completely different from the land-based system in terms of energy demand and environmental attributes (solar irradiance, wind speed). Even though some studies cover nuclear propulsion systems and the integration of renewable and fossil fuel in maritime transportation, extensive analysis of N-R HES in maritime vessels is first of a kind in this area.

Nuclear power in marine vessels is not a new idea. There were about 700 naval nuclear reactors and 200 of them are still in operation for military use [8]. In the past, there were also nuclear-powered merchant ships. In 1962, a nuclear-powered cargo/passenger ship 'NS Savannah' was built. The cargo and passenger carrying capacity of this ship was 10,000 tons and 60 passengers, respectively. Around 90 million dollars was spent to build this ship and 12 million was earned in the 5 years operation. This ship used low enriched uranium, and the civil work was completed by the Westinghouse. The ship was abandoned in 1971 due to economic competitiveness, lack of component reliability, and wage dispute between nuclear engineers and deck workers. The nuclear-powered German ship 'NS Otto Hann' was ordered in 1962 to the shipyard 'Kieler Howaldtswerke AG'. It was in operation for 10 years and was dismantled in 1979. This ship was traveled around 650,000 nautical miles. This ship faced regulatory issues, like refusal from many port authorities to enter into the ports. Due to the restriction from port authorities and high operating costs, the ship was taken off earlier than expected. This ship used compact PWR specially made for that ship. Japan built the 'NS MUTSU' which reactor power rating was 36 MW. This ship was completed in 1972 and just after the first test announcement, local people including fishermen protested against it. However, the government managed to test in the deep sea with low power in 1974. During the test, when the reactor reached $1.4 \%$ of its' total power, neutron radiation was detected outside the nuclear shielding. The ship was undergone major repair and was completed again in 1991. Due to negative public perception and multi companies involvement, this ship was decommissioned in 1992. In this paper, the authors summarized the past nuclear-powered merchant ships in terms of the timeline of the ships, types of reactors, engineering designs, and underlying reasons for the success and failures. They pointed out social issues like the different public perceptions about the nuclear safety of nuclear-powered merchant ships and military ships. They also explained how nuclear accidents affect the public acceptance of nuclear ships. The authors concluded that nuclear propulsion is economically feasible and people engagement is important for the success of nuclear propulsion which can be achieved by informing the gain of using nuclear power and minimizing the misinformation about it.

The recent development in nuclear-powered marine ships and review of the past work was studied in [9]. In this study, a concept design of a cargo ship, powered by a 25 MWe. SMR was proposed. The authors analyzed the risks associated with SMR location in the ship and different power train systems. This study identifies the aft of the cargo tank as the preferable location of SMR.

The feasibility of integrated solar PV, fuel cell, and diesel generator in a cruise ship is studied in [10]. The cruise ship operates in the baltic sea between Mariehamn (the Aland Islands) and Stockholm (Sweden). The authors used an optimization technique to determine the optimal configuration of the system components. In the latter part, this hybrid system is compared with the conventional diesel-electric system in terms of COE, renewable energy penetration, and $\mathrm{CO}_{2}$ emissions. They concluded the hybrid energy system had higher renewable energy penetration, and lower $\mathrm{CO}_{2}$ emissions. However, the COE is higher in the Hybrid energy system due to the high upfront cost of renewable energy systems, and the lower availability of solar irradiance in the considered sea route. 
The authors proposed that this hybrid system could be cost-effective if it was considered in an area where the solar irradiance is high like Sharjah, UAE.

A comparison of hybrid energy systems between land-based systems and marine ship was conducted in [11]. The authors considered an oil tanker that started its' voyage from Dalian in China and ended at Aden in Yemen. Two diesel generators and solar PV system were considered in the hybrid energy system. The average solar radiation of the six ports in the ship navigation route was considered for both the marine ship and land-based system. Although no limitation was considered for the land-based system to install solar PV, the authors limited the solar PV system to $300 \mathrm{~kW}$ considering the available area for solar PV installation in the oil tanker. The authors analyzed four types of energy systems, namely 'Diesel Generator, Solar PV, and Battery Energy System', 'Diesel Generator and Solar PV Energy System', 'Diesel Generator and Battery Energy System', and 'Only Diesel Generator Energy System'. As there is no renewable energy for 'Only Diesel Generator Energy System' and 'Diesel Generator and Battery Energy System', the NPC, COE, and GHG emissions are the same in ship and land-based system for these two energy systems. This study concludes that for both ship and land-based systems, 'Diesel Generator, Solar PV, and Battery Energy System' is the optimal solution. However, the GHG emissions are nine times higher in ship compared to the land-based system due to limited penetration of solar PV in the oil tanker.

Several studies have been done on land-based N-R HES systems. The financial analysis of nuclear-renewable energy integration was carried out in [12]. The authors considered three cases, namely nuclear/hydrogen/wind hybrid energy system, nuclear/wind energy system, and only nuclear energy system. They compared the three scenarios based on the payback period, Cost of Energy (COE), Internal Rate of Return (IRR), and Net Present Value (NPV). They concluded that for energy generation in the future, nuclear/hydrogen/wind hybrid energy system could be a feasible project.

An alternative of diesel generator in a MEG was examined in [13]. The authors considered Microreactor (MR) as a possible candidate to replace the diesel generator within a MEG of Ontario Tech University (UOIT). They considered both the electric and thermal demand of UOIT. They used Particle Swarm Optimization (PSO) to minimize the Net Present Cost of the hybrid energy systems and find out the optimal configuration of it. The hybrid energy system contained wind turbine, solar PV, hydropower, Biogas Generator (BG), and diesel generator. To check the feasibility of the MR as an alternative to DG, the authors replaced the DG with MR in the hybrid energy systems. The electrical demand was fulfilled by the wind turbine, solar PV, diesel generator, and hydro turbine. The thermal demand was supplied by diesel generator and biogas generator. They employed a CHP unit to utilize the waste heat from the DG and BG. To store the electrical energy, they used electrochemical energy storage (EES) and hydrogen storage. The technical and economic KPIs such as Loss of Power Supply Probability (LPSP), Surplus Energy Fraction (SEF), Level of Autonomy (LA), NPC, and LCOE were studied in this paper. They concluded that MR could be an outstanding replacement for the diesel generator considering the technical and economic KPIs for land-based MEG.

Three types of nuclear-renewable hybridization were presented in [14]. The authors discussed "Direct Coupling", "Single Resource and Multiple products-based coupling", and "Multiple Resources and Multiple products-based coupling". The mathematical model of N-R MHES's economy was done MATLAB software. To achieve the optimal system configuration and to minimize the Net Present Cost (NPC), Particle Swarm Optimization was used in this study. This study identifies "Multiple Resources and Multiple productsbased Coupling" has the lowest NPC, and it has 1.8 times and 1.3 times lower NPC than "Direct Coupling" and "Single Resource and Multiple product-based coupling," respectively. A sensitivity analysis was carried out by varying the peak demand, seasonal demand, average energy demand, system equipment cost, project lifetime, inflation rate, discount rate, and capacity factor to strengthen the findings. 
An oil tanker, 'Baltic Sunrise' is considered as the reference ship in this study to check the feasibility of nuclear renewable hybrid energy system in maritime transportation in comparison with other energy systems. Microreactor (MR) is considered as the source of nuclear energy in this study. The outline of this document is as follows: Section 2 covers the system configuration including the shipping route, energy estimation of the ship, and modeling of different components of the energy systems. The key performance indicators (KPIs) that are used to measure the performance of different energy systems are discussed in Section 3. Section 4 is all about the formation of the optimization problem. Section 5 presents the result while Section 6 covers the sensitivity analysis to reinforce the findings. The conclusion and future scope of work are discussed in Section 7.

The framework of this study is illustrated in Figure 1. The literature review is carried out to understand the problem and the gap of previously suggested solutions. The N-R HES analysis in marine transportation requires a lot of data like ship speed to estimate the energy demand, solar irradiance to calculate the solar PV output, and wind speed to determine the wind power of wind turbine. These data are collected from FleetMon (A vessel data collection Company) and NASA Surface meteorology and Solar Energy database. After getting these data, the energy requirement of the ship, solar power, and wind power are calculated. The planning of the energy systems is completed by designing the system components and identifying the system KPIs. All the energy systems are then optimized to determine the lowest NPC. The mathematical cost model of the energy systems is carried out in MATLAB Software. The objective functions, constraints, and decision variables are formulated to optimize the models by DE, ADE, and PSO optimization techniques. Primarily, the DE algorithm is used to identify the optimal energy systems and sensitivity analyses. The ADE is employed to understand the impact of control parameters on the DE algorithm. The PSO is used to measure the performance and validate the findings of the $\mathrm{DE}$ algorithm. As the N-R HES in marine transportation employs several variables like economic parameters, and meteorological resource availability, a sensitivity analysis is conducted in this study to reinforce the findings. 


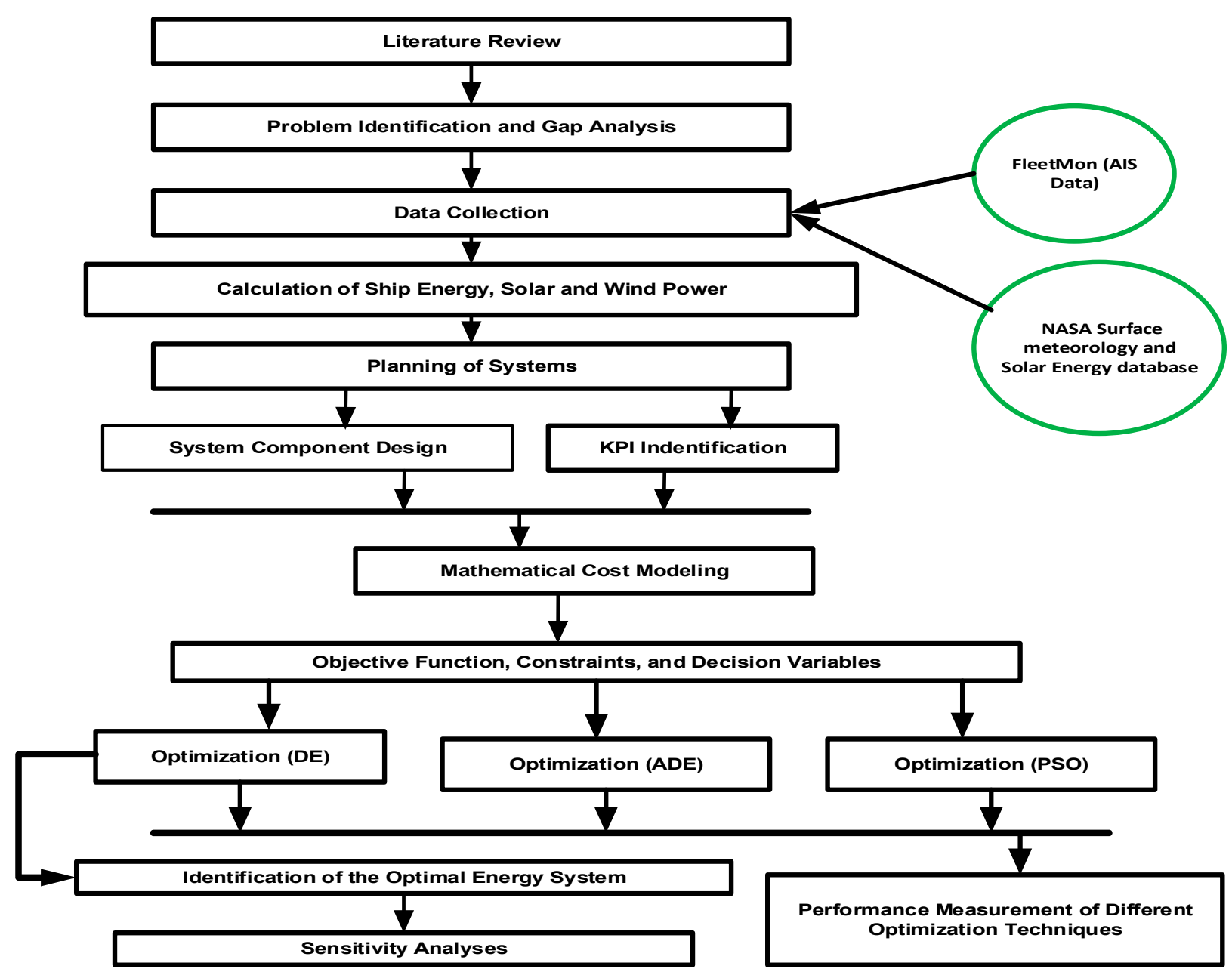

Figure 1. Framework of the Study.

\section{System Modeling}

An oil tanker called 'Baltic Sunrise' is studied in this paper. Automatic Identification System (AIS) data of this ship is collected from a vessel data collection company named 'FleetMon'. There are MRs, wind turbines, solar PV panels, energy storage systems, controllers, and converters in the proposed system. Estimation of the energy demand of the ship is calculated by using the AIS data. The system's project lifetime is 40 years with the inflation rate and the discount rate as $2 \%$ and $8 \%$, respectively. Renewable energy resource data is collected from the NASA Surface meteorology and Solar Energy database. The study considers the lifecycle cost of MR and diesel generators to make the analysis more practical. This research also addresses the system's reliability and constraints of implementing energy systems in marine vessels due to the limited area and cargo carrying capacity of the ship. Four energy systems, namely 'Nuclear Renewable Hybrid Energy Systems (N-R HES)', 'Standalone Fossil Fuel-based Energy System', 'Fossil Fuel and Renewable Hybrid Energy System', and 'Standalone Nuclear Energy System', are studied here. Matlab software is used to model the cost of each energy system. All the systems are then optimized by using the Differential Evolution Algorithm (DEA) to find out the optimal system configuration with minimal NPC. The study compares all the optimized systems to identify the best energy system for maritime transportation. The Particle Swarm Optimization (PSO) is used to measure the performance of the Differential Evolution Algorithm (DEA), and validate the findings of $\mathrm{DE}$ optimization technique. To analyze the impact of the control parameters of the DE, Adaptive Differential Evolution (ADE) is employed in this study. A sensitivity analysis is accomplished to see the impact of different system parameters. 


\subsection{Ship, Route Description, and Energy Estimation}

'Baltic Sunrise' is considered in this case study. IMO number, Length Overall (LOA), Length between Perpendicular (LBP), Extreme breadth (Beam), Deadweight, and Displacement of this ship are 9,307,633, 333.12 m, $324.00 \mathrm{~m}, 60.04 \mathrm{~m}, 309,373 \mathrm{MT}$, and 352,410 MT, respectively. This ship starts its voyage on 1 May 2019 from Iraq and ends in Singapore on 31 July 2019 via Egypt and Netherland. The speed of this ship was different in different positions. The maximum speed of this ship was $17.8 \mathrm{kn}$ with an average speed of $11.94 \mathrm{kn}$. The maximum draught and minimum draught of the ship were $21.6 \mathrm{~m}$ and $10.7 \mathrm{~m}$, respectively [15].

The effective ship propulsive power is calculated in each position using the speed of the ship in that position, draught, breadth, residual resistance, and frictional resistance. ITTC-57 method and Gertler series data chart are used in this calculation. Appendix A summarizes the parameters and assumptions that are considered during the calculation of the estimation of ship electric power. Detail calculation of estimating the energy demand of the ship can be found in [16-18].

The maximum rating of propulsive electric power of this ship is $24.64 \mathrm{MW}$. Another type of electric power, namely 'Auxiliary Load', is considered along with propulsive power. Auxiliary load emulates the electrical load demand for light, cooling, feed systems, pumps, and air compressors. Grzegorz et al. [19] assessed the auxiliary load to propulsive load ratio for different types of maritime vessels by collecting the data from ships register, logbook record and interviewing the captains of ships, chief engineers, and stations pilot. For oil tankers, they found the ratio as 0.211 . Appendix B shows the yearly propulsive electric power (MW) and yearly total load demand with auxiliary load (MW).

\subsection{Diesel Generator}

Fossil Fuel-based Generator (FFG) is considered in this study for comparing the proposed N-R HES with the conventional energy systems of ocean-going marine ships. A marine vessel's traditional energy system consists of a main engine, auxiliary engine, heat recovery steam generator, and shaft generator [5]. The cost of a diesel generator can be categorized broadly into three major categories- 'Capital Cost', 'Operating Cost', and 'Decommissioning Cost'. Since the decommissioning cost of a diesel generator is minimal, it can be ignored.

The Generator Size, Capital Cost, Replacement Cost, Fixed O \& M cost, Lifetime, $\mathrm{CO}_{2}$ emission, and Fuel cost of diesel generator are 1000 (kW), 800 (USD/kW), 800 (USD/kW), 35 (USD/kW/Year), 2.5 (Years), 700 (kg/MWh), and 202 (USD/MWh), respectively [14], [20].

\subsection{Solar Energy}

Solar PV systems convert sunlight into electricity. The generation of solar power from solar PV depends on the ambient temperature, solar irradiance, and solar PV area. The output power from solar PV can be calculated by using the following equation [21].

$$
P_{S P V}(t)=N u m_{S P V} \times n_{S P V}(t) \times P V_{A} \times R_{t}(t) \quad \forall t \in t_{\text {total }}
$$

where, $P_{S P V}(t)$ is the output power from the solar PV $(\mathrm{W}), \mathrm{Num}_{S P V}$ is the number of solar $\mathrm{PV}, n_{S P V}(t)$ is the instantaneous efficiency of the solar PV, $P V_{A}$ is the area occupied by the solar PV $\left(5 \mathrm{~m}^{2}\right)$, and $R_{t}(t)$ is the solar irradiance $\left(\mathrm{W} / \mathrm{m}^{2}\right)$.

The instantaneous efficiency of the solar PV can be obtained by the following equation [22].

$$
n_{S P V}(t)=n_{p v-r e f} \times n_{M P P T} \times\left[1+\beta\left(T_{\mathcal{c}}(t)-T_{c-r e f}\right)\right] \quad \forall t \in t_{\text {total }}
$$

where, $n_{S P V}(t)$ is the instantaneous efficiency of the solar PV (\%), $n_{p v-r e f}$ is the reference efficiency of the solar PV (\%), $n_{M P P T}$ is the efficiency of the Maximum Power Point Tracking (MPPT) unit which is 1 in this study, $T_{\mathcal{C}}(t)$ is the temperature of the PV cell $\left({ }^{\circ} \mathrm{C}\right)$ at time step 
$t, T_{c-r e f}$ is the reference temperature of the PV cell, and $\beta$ is the temperature coefficient of efficiency $\left({ }^{\circ} \mathrm{C}^{-1}\right)$.

The PV cell temperature can be obtained by the proposed PV model by Markvar [23].

$$
T_{\mathcal{c}}(t)=T_{a}(t)+\left(\frac{N O C T-20}{800}\right) \times R_{t}(t) \quad \forall t \in t_{\text {total }}
$$

where, $T_{a}(t)$ is the ambient temperature at time step $t$, and NOCT is the normal operating temperature. The Capital Cost, Replacement Cost, O\&M Cost, Lifetime, Reference Efficiency of PV Panel, Efficiency of the MPPT unit, Temperature Coefficient, PV panel reference temperature, and Nominal Operating Cell Temperature are $640(\$ / \mathrm{kW}), 640(\$ / \mathrm{kW})$, $12(\$ / \mathrm{kW} /$ Year $), 25$ (Years), $24(\%), 100(\%),-0.0041\left({ }^{\circ} \mathrm{C}^{-1}\right), 25\left({ }^{\circ} \mathrm{C}\right)$, and $45\left({ }^{\circ} \mathrm{C}\right)$, respectively [24], [25], [26], [22], [27].

The hourly data for one year holds a total of 8760 data points. The solar radiation differs in the shipping route with longitude and latitude, time, and date. To keep the calculation simple, the data solar irradiance and temperature are considered based on the monthly position of the ship in the adjacent ports. Appendix $C$ represents the hourly solar irradiance and temperature for one year, respectively. The usable area of the marine ship for solar PV installation is limited. Solar PV systems must not hinder the transfer area and must not conceal any area with financial impact [28]. This study addresses this constraint while planning the optimal configuration of the system components.

\subsection{Wind Power}

The wind is a great source of energy and has the potential to generate electricity without any fuel. Several models can be used to estimate the output power of the wind turbine, like the model based on Weibull parameters [29,30], the linear model [31,32], and the quadric model. In this study, the quadric model is used. To calculate the output power of the wind turbine, the wind speed at hub height needs to be obtained by the following equation.

$$
V_{\text {whub }}(t)=V_{\text {wref }}(t) \times\left(\frac{H_{\text {whub }}}{H_{\text {wref }}}\right)^{\mu} \quad \forall t \in t_{\text {total }}
$$

where, $V_{\text {whub }}(t)$ is the wind speed at the hub height $(\mathrm{m} / \mathrm{s})$ at time step $t, V_{\text {wref }}(t)$ is the wind speed at the anemometer height $(\mathrm{m} / \mathrm{s})$ at time step $t, H_{\text {wref }}$ is the anemometer height (m), $H_{\text {whub }}$ is the hub height (m), and $\mu$ is the power-law coefficient of the wind speed.

After measuring the wind speed at the hub height, it is used to calculate the wind turbine power by using the following equations [33].

$$
P_{W}(t)=\left\{\begin{array}{cl}
0, & V_{\text {whub }}(t)<V_{\text {cin }}, V_{\text {whub }}(t)>V_{\text {cout }} \\
\frac{P_{r}}{V_{r}^{3}-V_{\text {cin }}^{3}} \times V_{\text {whub }}^{3}(t)-\frac{V_{\text {cin }}^{3}}{V_{r}^{3}-V_{\text {cin }}^{3}} \times P_{r}, & V_{\text {min }} \leq V(t) \leq V_{r} \\
P_{r}, & V_{r} \leq V(t) \leq V_{\text {max }}
\end{array}\right.
$$

where, $P_{W}(t)$ is the output power of the wind turbine $(\mathrm{kW})$ at time step $t, P_{r}$ is the rated power of the wind turbine $(\mathrm{kW}), V_{r}$ is the rated wind speed of the wind turbine $(\mathrm{m} / \mathrm{s})$, $V_{\text {cin }}$ is the cut-in speed of the wind turbine $(\mathrm{m} / \mathrm{s}), V_{\text {cout }}$ is the cut-out wind speed $(\mathrm{m} / \mathrm{s})$, and $V_{\text {whub }}$ is the measured wind speed at the hub height $(\mathrm{m} / \mathrm{s})$. The hourly wind speed is presented in Appendix C. The Nominal Capacity, Capital Cost, Replacement Cost, O\&M Cost, Lifetime, Hub Height, Anemometer Height, Minimum wind speed, Maximum wind speed, Rated wind speed, and Power Law Exponent are $50 \mathrm{~kW}, 1130$ \$/kW, 1130 $\$ / \mathrm{kW}, 48$ \$ $/ \mathrm{kW} /$ Year, 25 Years, $45 \mathrm{~m}, 50 \mathrm{~m}, 3 \mathrm{~m} / \mathrm{s}, 25 \mathrm{~m} / \mathrm{s}, 10 \mathrm{~m} / \mathrm{s}$, and 1/7, sequentially [34], [35], [36], [37], [38], [39], [40]. 


\section{5. $v S M R / M R$}

This study evaluates the lifecycle cost of vSMR and focuses on the economic model of it. SMR is a fourth-generation nuclear reactor having power equivalent to $300 \mathrm{MWe}$ or less. Modular fabrication, passive safety systems, and enhanced protection against man-made or natural hazards are some advanced features of SMR. A subcategory of SMR is vSMR, which power rating is less than 15 MWe [41]. Another subcategory of SMR is Microreactor (MR), which typically ranges from 1 MWe to 50 MWe [42].

Based on the lifecycle phases of SMR and nuclear fuel, the cost of vSMR can be divided into three major categories that are capital costs, annual operating costs, and backend costs [20]. The first deployment cost of any technology is always higher compared to the subsequent deployment. The rate of cost reduction of the next deployment depends on the lesson learned from the prior deployment. The cost reduction depends on the learning rate of the factories. The learning rate refers to the cost reduction of a factory that can be achieved by experience and learning how to execute a process and use different tools to deliver a product. The learning rate of SMR could be $8 \%$ to $10 \%$. The relation between learning rate and cost reduction can be expressed by the following equation [16].

$$
R=\log 2(1-\mathrm{LR})
$$

where, $R$ is the rate cost reduction, and LR is the learning rate. In this study, the learning rate is considered as $10 \%$ [13]. The relation between the vSMR capital cost and the rate of cost reduction can be expressed by the following equation.

$$
v S M R C_{u}=v S M R C_{1 s t} \times N_{t h}{ }^{R}
$$

where, $v S M R C_{u}$ is the unit cost of $N_{t h} \mathrm{vSMR}(\$), v S M R C_{1 s t}$ is the 1st vSMR cost (\$), and $R$ is the rate of cost reduction.

vSMR is capable to perform both baseload operation and load-following operation. However, the SMR vendor outlines that load following feature of SMR affects the main steam supply and coolant system components and frequent replacement might be required. During the Extended Reduced Power Operation (ERPO), reactors can operate as low as 30\% of its' rated power for several days to several months. In this study, the baseload operation of VSMR is considered for all the time except the time of loading and unloading the cargo/liquid (oil) in the port when ERPO ( $30 \%$ of the rated power) is considered. Although there are no $\mathrm{CO}_{2}$ emissions during the operation of SMR, $\mathrm{CO}_{2}$ emits in the lifecycle of SMR, mainly in the construction stage due to concrete production and in the fuel processing stage due to the high demand for electricity and fossil fuel. The Reactor size, Plant lifetime, Overnight capital cost, Fixed O\&M cost, Fuel cost, Refueling cost of fuel module, Core lifetime, Decommissioning cost, Capacity factor, Plant efficiency, and $\mathrm{CO}_{2}$ emission are 1000 (kWe), 40 (Years), 15,000 (\$/kWe), 350 (\$/kWe), 10 (\$/MWh), 20 (million \$), 10 (Years), 5 (\$/MWh), $95(\%), 40(\%)$, and $4.55(\mathrm{~kg} / \mathrm{MWh})$, respectively [20], [43].

\subsection{Electrochemical Energy Storage}

The EES is considered in this study to store the excess energy in the form of chemicals and supply when it requires. The rating of the EES depends on the rating of the load, autonomy hour, depth of discharge of the battery, the efficiency of the battery, and the inverter. The rating ( $\mathrm{kWh}$ ) of the battery can be expressed by the following equation [44].

$$
B A T_{\text {rating }}=\frac{P_{\text {load }} \times A H \times N_{\text {bat }}}{D O D_{b a t} \times n_{\text {inv }} \times n_{\text {bat }}}
$$

where, $P_{\text {load }}$ is the rating $(\mathrm{kW})$ of the load, $A H$ is the autonomy hours, $N_{b a t}$ is the number of battery, $D O D_{b a t}$ is the depth of discharge of the battery, $n_{i n v}$ is the efficiency of the inverter, and $n_{b a t}$ is the efficiency of the battery. In this study, the load is considered as $70 \mathrm{~kW}$ [45]. The autonomy hour refers to the required amount of time to serve the load 
continuously in an emergency. The autonomy hour is between $12 \mathrm{~h}$ to $18 \mathrm{~h} \mathrm{[46].} \mathrm{In} \mathrm{this}$ paper, autonomy hour is taken as $18 \mathrm{~h}$. The $D O D_{b a t}, n_{\text {inv }}$, and $n_{b a t}$ is $80 \%$ [46], 95\% [47], and $85 \%$ [48], respectively.

The state of charge (SOC) of the battery bank depends on the DOD and rating of the battery. The maximum and minimum SOC of the battery can be calculated by the following equations.

$$
\begin{gathered}
B A T_{S O C, \text { min }}=B A T_{\text {rating }} \times\left(1-D O D_{\text {bat }}\right) \\
B A T_{S O C, \text { max }}=B A T_{\text {rating }} \times D O D_{\text {bat }}
\end{gathered}
$$

where, $B A T_{S O C, \max }$ is the maximum SOC of the battery bank, and $B A T_{S O C, \min }$ is the minimum SOC of the battery bank. The charging and discharging of the battery bank at any time step depend on the available energy that can be given to the battery bank, the amount of energy that is needed from the battery bank, and the SOC of the battery bank in the previous time step. $B A T_{S O C, \min }$ is considered as the initial SOC of the battery in this paper.

The energy that can be given to the battery and the energy that is needed from the battery bank depend on the total energy generation and total load demand of the system. The below equations are used to calculate the amount of energy that can be given and the amount of energy that is needed from the battery bank.

$$
\begin{array}{cr}
B A T_{\text {inm }}(t)=\left(P_{\text {genm }}(t)-P_{L}(t)\right) \times n_{\text {bat }} ; & P_{\text {gen }}(t)>P_{L}(t) \\
B A T_{\text {outm }}(t)=\frac{P_{L}(t)-P_{\text {gen }}(t)}{n_{\text {bat }}} ; & P_{\text {gen }}(t)<P_{L}(t) \\
P_{\text {gen }}(t)=P_{p v}(t)+P_{w}(t)+P_{v S M R}(t) & \forall t \in t_{\text {total }} \\
P_{\text {gen }}(t)=P_{p v}(t)+P_{w}(t)+P_{G N R T}(t) & \forall t \in t_{\text {total }}
\end{array}
$$

where, $B A T_{\text {inm }}(t), B A T_{\text {outm }}(t), P_{\text {genm }}(t), P_{L}(t), P_{p v}(t), P_{w}(t), P_{v S M R}(t), P_{G N R T}(t)$ is the amount of energy that can be given to the battery bank, the amount of energy that is needed from the battery bank, the total electric energy generation, the total electric load, the total electric energy from the solar panel, the total electric energy from the wind turbine, the total electric energy from MR, and the total electric energy from diesel generator at the time step $(t)$, respectively.

The amount of energy that the battery bank can take and give at any time step can be formulated by the below equations.

$$
\begin{gathered}
B A T_{S O C, \text { min }} \leq B A T e(t-1) \leq B A T_{S O C, \text { max }} \\
B A T_{\text {take }}(t)=B A T_{S O C, \text { max }}-B A T e(t-1) ; \quad \forall t \in t_{\text {total }} \\
B A T_{\text {give }}(t)=B A T e(t-1)-B A T_{S O C, \text { min }} ; \quad \forall t \in t_{\text {total }}
\end{gathered}
$$

where, $B A T e(t-1)$ is the battery energy at time step $(t-1), B A T_{\text {take }}(t)$ is the amount of energy that can be taken by the battery bank at the time step $(t)$, and $B A T_{\text {give }}(t)$ is the amount of energy that can be given by the battery bank at the time step $(t)$.

The battery capacity after charging and discharging at time step $(t)$ depends on the load demand, total energy generation, maximum SOC, minimum SOC, and battery capacity at time step $(t-1)$. The charging and discharging of the battery bank can be formulated by using the below equations

$$
\begin{gathered}
B A T_{\text {chrg }}(t)=B A T_{S O C, \text { max }} ; \quad P_{\text {gen }}(t)>P_{L}(t) \& B A T_{\text {in }}(t) \geq B A T_{\text {take }}(t) \quad \forall t \in t_{\text {total }} \\
B A T_{\text {chrg }}(t)=B A T e(t-1)+B A T_{\text {in }}(t) ; \quad P_{\text {gen }}(t)>P_{L}(t) \& B A T_{\text {in }}(t)<B A T_{\text {take }}(t) \quad \forall t \in t_{\text {total }} \\
B A T_{\text {dischrg }}(t)=B A T_{S O C, \text { min }} ; \quad P_{\text {gen }}(t)<P_{L}(t) \& B A T_{\text {out }}(t) \geq B A T_{\text {give }}(t) \quad \forall t \in t_{\text {total }} \\
B A T_{\text {dischrg }}(t)=B A T e(t-1)-B A T_{\text {out }}(t) ; \quad P_{\text {gen }}(t)<P_{L}(t) \& B A T_{\text {out }}(t)<B A T_{\text {give }}(t) \quad \forall t \in t_{\text {total }}
\end{gathered}
$$




$$
B A T_{e}(t)=B A T e(t-1) ; \quad P_{\text {gen }}(t)=P_{L}(t) \quad \forall t \in t_{\text {total }}
$$

where, $B A T_{\text {chrg }}(t), B A T_{\text {dischrg }}(t)$, and $B A T_{e}(t)$ refer to the battery capacity after charging, battery capacity after discharging, and battery capacity when energy generation and demand are exactly the same, respectively at time step $(t)$. If there is any excess energy that will be dumped. The Capital Cost, Replacement Cost, O\&M Cost, Lifetime, Efficiency, Depth of Discharge, and Inverter Efficiency are $398(\$ / \mathrm{kWh}), 398$ (\$/kWh), 10 (\$/kWh/Year), 5 (Years), $85(\%), 80(\%)$, and $95(\%)$, respectively.

\section{Key Performance Indicators}

The KPIs are used to compare different energy systems to evaluate the feasibility. This study employs technical, economical, and environmental KPIs as follows.

\subsection{Net Present Cost (NPC)/Net Present Value (NPV)}

The Net Present Cost (NPC) and Net Present Value (NPV) are similar concepts and they only differ in sign. The NPV is the present value of all future cash flows (positive and negative) of an investment with a discount rate [49]. The lower NPC implies a higher profit to the investors. The following equation can be used to calculate the NPC. As NPV and NPC differ only in sign, NPC and NPV are related as follows.

$$
\begin{gathered}
\text { Net Present Cost }(\mathrm{NPC})=- \text { Net Present Value }(\mathrm{NPV}) \\
\qquad \begin{array}{c}
\mathrm{NPV}=\frac{\text { Cash flow }}{(1+\mathrm{rld})^{\mathrm{t}}}-\text { Initial Investment } \\
\quad r l d=\frac{\mathrm{i}-f}{1+f}
\end{array}
\end{gathered}
$$

where, $r l d, f, i$, and $t$ denote the real discount rate (\%), nominal discount rate $(8 \%)$, inflation rate $(2 \%)$, and time periods number, respectively. In the nominal discount rate/interest rate, the inflation rate is covered. To factor out the impact of the inflation rate, the real discount rate is considered in this study. The equation for calculating the real interest rate is also known as Fisher equation [50].

For calculating the NPC for a longer project lifetime with multiple cash flows, the formula can be modified as per the below equation.

$$
\mathrm{NPV}=\sum_{\mathrm{t}=0}^{\mathrm{n}} \frac{\mathrm{R}_{\mathrm{t}}}{(1+r l d)^{\mathrm{t}}}
$$

where $\mathrm{R}_{\mathrm{t}}$ and $\mathrm{n}$ refer to net cash inflow-outflow in a unit time period, and project lifetime, respectively.

\subsection{Levelized Cost of Energy (LCOE)}

The LCOE is the ratio of the total annualized system cost (\$) to the total electricity $(\mathrm{kWh})$ delivered by the system annually [51]. The lower LCOE refers to the lower unit price of the energy the system can serve which implies a higher profit to the investors. The LCOE is expressed by the following equation [13].

$$
L C O E=\frac{N P C_{\text {total }}}{\sum_{t=1}^{8760}\left(P_{\text {gen }}(t)\right) \times \Delta t} \times \frac{i(1+r l d)^{n}}{(1+r l d)^{n}-1}
$$

where, $N P C_{\text {total }}$ is the total NPC of the system (\$). $P_{\text {gen }}(t)$ is the energy generation from the system at time step $t, n$ is the project lifetime (40 years), and $\Delta t$ is the time step considered in the analysis. 


\subsection{Generation Reliability Factor (GRF)}

GRF is one of the reliability factors that indicate the amount of demand of a system is accomplished by the energy system [14]. The mathematical formula of GRF for the demand of the system can be expressed by the following equation [13].

$$
G R F_{e}=\frac{\sum_{t=1}^{t_{\text {total }}} P_{\text {gen }}(t) \times \Delta t}{\sum_{t=1}^{t_{\text {total }}} P_{L}(t) \times \Delta t} \times 100 \% \quad \forall t \in t_{\text {total }}
$$

where, $G R F_{e}$ is the generation reliability factor. $P_{g e n}(t)$ and $P_{L}(t)$ represent the power generation and electric load demand at time step $t$. $\Delta t$ shows the time step considered in the calculation. The higher value of GRF implies the system is more reliable.

\subsection{Loss of Power Supply Probability (LPSP)}

The LPSP is another reliability factor that determines the amount of unserved energy of a system when the system demand is higher than the generation. To ensure the reliability of the system, it is important to maintain the LPSP within a boundary. Therefore, this KPI is considered as one of the constraints in the optimization of the system. The LPSP is determined for each time step and for the total time step to assure the utmost reliability of the system. The following equations are used to determine the LPSP [13].

$$
\begin{array}{ll}
\operatorname{LPSP}_{e}=\frac{\sum_{t=1}^{t_{\text {total }}}\left(P_{L}(t)-P_{\text {gen }}(t)\right)}{\sum_{t=1}^{t_{\text {total }}} P_{L}(t)} \times 100 \% & P_{L}(t)>P_{\text {gen }}(t) \\
\operatorname{LPSP}_{e}(t)=\frac{P_{L}(t)-P_{\text {gen }}(t)}{P_{L}(t)} \times 100 \% & P_{L}(t)>P_{\text {gen }}(t)
\end{array}
$$

where, $L P S P_{e}$ represents the loss of power probability for the total time step, $L P S P_{e}(t)$ shows the loss of power probability at each time step. The maximum and minimum value of LPSP is 1 and 0 , respectively. The lower LPSP infers the higher reliability of the system.

\section{5. $\mathrm{CO}_{2}$ Gas Emissions}

Several pollutants are emitted from the energy generators namely Carbon Monoxide, Particulate matter, Nitrogen Oxides, Carbon Dioxide, Sulfur Dioxide, and Unburned Hydrocarbons (UHC) in the lifecycle of the generators. In this study, only $\mathrm{CO}_{2}$ gas emission is considered. The amount of $\mathrm{CO}_{2}$ emissions from any generators is calculated by the following equation [52].

$$
\mathrm{CO}_{2} \text { emissions }=\text { Emission Factor }\left(\frac{\mathrm{kg}}{\mathrm{MWh}}\right) \times \mathrm{TAEG}(\mathrm{MWh})
$$

where, TAEG is the total annual electricity generation from the generators. The emissions factor for diesel generators and SMR is $700 \mathrm{~kg} / \mathrm{MWh}$ and $4.55 \mathrm{~kg} / \mathrm{MWh}$, respectively [20], [53]. The penalty for $\mathrm{CO}_{2}$ emissions is considered during the calculation of NPC. The annual penalty for $\mathrm{CO}_{2}$ emissions can be calculated by using the following equation.

$$
C C E=A C E \times C E P \times \frac{i(1+r l d)^{n}}{(1+r l d)^{n}-1}
$$

where, $C C E$ is the cost associated with $\mathrm{CO}_{2}$ emissions penalty (\$), $A C E$ is the annual $\mathrm{CO}_{2}$ emissions (tonne), and $C E P$ is the $\mathrm{CO}_{2}$ emissions penalty (\$/tonne). Although nation-wise carbon tax varies a lot, IMF calculated large $\mathrm{CO}_{2}$ emitter countries should be charged between $50 \mathrm{USD} /$ ton to $100 \mathrm{USD} /$ ton by 2030 to fulfill their commitments to lessen the carbon emissions [54]. For the shipping industry, IMF proposed $30 \mathrm{USD} /$ ton $\mathrm{CO}_{2}$ emissions as a penalty [55]. In this study $30 \mathrm{USD} /$ ton $\mathrm{CO}_{2}$ emissions is considered as $\mathrm{CO}_{2}$ emissions penalty to show the impact on NPC and LCOE. 


\subsection{Power to Weight Ratio (PWR)}

The $P W R$ is an important criterion to choose the energy system for the marine ship. The PWR measures the performance of any power source or system. The heavyweight of power system of marine ships results in higher displacement and lower speed.

The higher $P W R$ allows the marine ship to carry more load while maintaining the high speed [56]. The PWR of a power system can be calculated by using the following equation [57].

$$
P W R=\frac{\text { Power rating of the system }(\mathrm{kW})}{\text { Weight of the system }(\mathrm{kg})}
$$

$P W R$ is considered as one of the constraints in the optimization problem. Appendix D shows the PWR of the different components of the system.

\section{Problem Formation}

This section covers the formation of the optimization problem including objective function, constraints, decision variables, and steps of DE, ADE, and PSO algorithm implementation.

\subsection{Objective Function}

The objective of the optimization problem is to identify the optimal configuration of the HES to achieve the lowest NPC. Along with the N-R HES, other three energy systems, namely 'Standalone Fossil Fuel-based Energy Sytems', 'Renewable and Fossil Fuel-based Hybrid Energy System', and 'Standalone Nuclear Energy System' are also optimized to compare with the proposed N-R HES. The objective function represents the economic KPI and the constraints of the optimization problem covering the technical and other KPIs, such as LPSP and PWR. The fitness function of the optimization problem is the total NPC of all the system components. The fitness function of the optimization problem can be formulated as below.

$$
\min f_{N P C}=\sum_{j \in K} N P C_{j}
$$

where, $K$ is the system component set, and $N P C_{j}$ refers to the NPC of the $j$ th component. The system comprises solar PV, wind turbine, MR, battery, and diesel generator. The NPC of any component represents the present value of the total cost of the component including capital cost, O\&M cost, cost of replacement, cost of fuel, and salvage value. For MRs, decommissioning cost and refueling cost are added as well. The NPC of any system component can be expressed as follows.

$$
N P C_{j}=C_{c a p c, j}+C_{r e p c, j}+C_{O \& M c, j}+C_{f u e l c, j}-C_{s a l v c, j} \quad \forall i \in G
$$

where, $C_{c a p c, j}, C_{r e p c, j}, C_{O \& M c, j}, C_{f u e l c, j}$, and $C_{s a l v c, j}$ represent the present value of capital cost, replacement cost, O\&M cost, fuel cost, and the salvage value of the $j$ th component, respectively. The salvage value of a component refers to the remaining value of a component at the end of the project lifetime where the component is used [58].

The capital cost of any component is calculated at the beginning of the project. The total capital cost involves the capital cost of each component and the number of components. The capital cost can be calculated by using the following formula.

$$
C_{c a p c, j}=N_{c o m, j} \times C_{c a p c, u n i t(j)} \quad \forall i \in G
$$

where, $C_{c a p c, j}, N_{c o m, j}$, and $C_{c a p c, u n i t(j)}$ refer to the capital cost, the number of components, and the unit cost of the $j$ th component, respectively.

The capital cost of MRs is calculated in a different formula as the cost of reduction is included in the capital cost. The rate of cost reduction of MRs is related to the learning rate, 
which is discussed earlier. The capital cost of MR can be calculated by using the formula as follows [59].

$$
C_{c a p c, M R}=\sum_{k=1}^{N_{M R}} C_{c a p c, M R(1 s t)} \times\left(N_{M R}\right)^{R}
$$

where, $C_{c a p c, M R}, C_{c a p c, M R(1 s t)}, N_{M R}$, and $R$ imply the total capital cost of MR, the unit price of the 1st MR, the number of MR, and the rate of cost reduction, respectively.

The O\&M cost of a component occurs each year and continues till the end of the project lifetime. The O\&M cost of a component is considered the same each year and is calculated by the following equation [60].

$$
C_{O \& M c, j}=N_{c o m, j} \times C_{O \& M, y e a r l y(j)} \times \frac{\left\{(1+r l d)^{n}\right\}-1}{r l d(1+r l d)^{n}} \quad \forall i \in G
$$

where, $C_{O \& M c, j}, N_{c o m, j}$, and $C_{O \& M, y e a r l y(j)}$ indicate the present worth of the total O\&M cost, number of components, and yearly O\&M cost of the $j$ th component, respectively.

The replacement of any component happens at the end of its' lifetime. The number of replacements depends on the component lifetime and the lifetime of the project. The present value of the replacement cost of the component is calculated as follows [60].

$$
\begin{gathered}
N R=\text { ceil }\left\lceil\frac{n}{C L T_{j}}\right\rceil-1 \\
F_{\text {rep }}=\sum_{k=1}^{N R}\left(k \times C L T_{j}\right) \\
C_{\text {repc }, j}=N_{\text {com }, j} \times \sum_{k=1}^{N R} C_{r e p, u n i t}(j) \times \frac{1}{(1+r l d)^{F_{\text {rep }}}} \quad \forall i \in G
\end{gathered}
$$

where, $C_{r e p c, j}$ is the present value of the replacement cost of the $j$ th component, $N R$ is the number of required replacement, $C L T_{j}$ is the lifetime of the $j$ th component, and $C_{r e p, u n i t}(j)$ is the per-unit replacement cost of the $j$ th component. ceil $(X)$ is a function that rounds $X$ to the nearest integer equal or greater than $X$.

The fuel cost is considered for MRs and fossil fuel-based generators. There is no fuel cost associated with renewable energy sources like solar PV and wind turbines. Also, there is no fuel cost for energy storage devices. The fuel cost is calculated yearly, and the present value of the fuel cost is formulated by using the below equation [60].

$$
\begin{gathered}
C_{f u e l c, j}=E_{y e a r l y, j} \times C U_{f u e l, j} \times \frac{\left\{(1+r l d)^{n}\right\}-1}{r l d(1+r l d)^{n}} \quad \forall j \in G \\
E_{\text {yearly }, j}=N_{c o m, j} \times R A T_{j} \times 365 \times 24 \quad \forall j \in G
\end{gathered}
$$

where, $C_{f u e l c, j}$ is the present worth of the fuel cost (\$) of the $j$ th component, $E_{y e a r l y, j}$ is the yearly energy generation $(\mathrm{MWh})$ from the $j$ th component, $C U_{f u e l, j}$ fuel price per unit energy generation of the $j$ th component, and $R A T_{j}$ is the rating of the $j^{4}$ component.

The salvage value of a component is the remaining useful value of a component at the end of the project lifetime. The linear depreciation is considered in the calculation of the salvage value. Linear depreciation refers that the salvage value of the component is directly proportional to the remaining life of the component. The present worth of the salvage value is calculated as follows [58].

$$
\begin{gathered}
C_{\text {salv }, j}=N_{\text {com }, j} \times C_{r e p, u n i t(j)} \times \frac{C L T_{\text {rem }, j}}{C L T_{j}} \times \frac{1}{(1+r l d)^{n}} \quad \forall i \in G \\
C L T_{r e m, j}=C L T_{j}-\left(n-L T_{r e p, j}\right)
\end{gathered}
$$




$$
L T_{\text {rep }, j}=C L T_{j} \times \text { floor }\left\lfloor\frac{n}{C L T_{j}}\right\rfloor
$$

where, $C_{s a l v, j}$ is the present worth of the salvage value of the $j$ th component, and $C L T_{\text {rem }}, j$ is the remaining year of the $j$ th component at the end of the project lifetime. floor $(X)$ is a function that rounds $X$ to the nearest integer equal or less than $X$.

The decommissioning cost and refueling cost are considered only for MRs. Although The decommissioning cost of MRs occurs at the end of the project, the annual distribution of decommissioning cost is considered in this study [43].

$$
C_{\text {decom }, M R}=E_{\text {yearly }, M R} \times C U_{\text {decom }, M R} \times \frac{\left\{(1+r l d)^{n}\right\}-1}{r l d(1+r l d)^{n}}
$$

where, $C_{\text {decom, } M R}$ is the present value of the total decommissioning cost (\$) of MR, $E_{\text {yearly, } M R}$ is the yearly energy generation ( $\mathrm{MWh}$ ) from the $\mathrm{MR}$, and $C U_{\text {decom, } M R}$ is the decommissioning cost per unit (\$/MWh).

The lifetime of the fuel module is considered 10 years in this study. Hence, the refueling of the MR occurs every ten years. The refueling cost of MRs does not include the cost of fuel. The refueling cost includes the cost associated with transportation of the fuel, labor cost, etc. The present value of the refueling cost is calculated by the following equations [60].

$$
\begin{gathered}
C_{\text {refueling, } M R}=N_{M M R} \times \sum_{k=1}^{M R_{\text {refuel }}} C_{\text {refueling, } M R(\text { unit })} \times \frac{1}{(1+\text { rld })^{F_{\text {refuel }}}} \\
M R_{\text {refuel }}=\text { ceil }\left[\frac{n}{L T_{f b(M R)}}\right]-1 \\
F_{\text {refuel }}=\sum_{k=1}^{M R_{\text {refuel }}}\left(n \times L T_{f b(M R)}\right)
\end{gathered}
$$

where, $C_{\text {refueling, } M R}$ is the present value of the refueling cost of the MR, $C_{\text {refueling,MR(unit) }}$ is the refueling cost in every 10 years, $L T_{f b(M R)}$ is the lifetime of the fuel bundle, and $M R_{\text {refuel }}$ is the number of the required refueling in the project lifetime.

\subsection{Constraints}

Constraints are used in the optimization problem to ensure the reliability, resiliency, and performance of the N-R HES. Some constraints are used to address some real-world limitations to implement the N-R HES in the marine ship.

The energy generation from any energy source must be equal to or less than the maximum capability of that energy source. This can be represented as follows.

$$
P_{\text {gen }}^{j}(t) \leq P_{\text {gen,max }}^{j} \quad \forall j, \forall t
$$

where, $P_{g e n}^{j}(t)$ is the electric generation of the $j^{t h}$ component at time step $t$ and $P_{g e n, \max }^{j}$ is the maximum electric generation capacity of the $j^{\text {th }}$ component at time step $t$.

To ensure the reliability and resiliency of the systems, the total generation of the system must be greater or equal to the total requirement of the system. The following equations are used to represent the constraints of the energy management of the system.

$$
\sum P_{\text {gen }}^{z}(t) \geq \sum_{t=1}^{t_{\text {total }}} P_{E L}^{z}(t) \quad \forall t \in t_{\text {total }}, \forall z
$$




$$
\sum P_{\text {gen }}^{z}(t)=\sum_{t=1}^{t_{\text {total }}} N u m_{P V} P_{p v}(t)+\sum_{t=1}^{t_{\text {total }}} N u m_{W T} P_{w}(t)+\sum_{t=1}^{t_{\text {total }}} N u m_{M R} P_{M R}(t) \quad \forall t \in t_{\text {total }}, \forall z
$$

where, $P_{\text {gen }}^{z}(t)$ is the generation of electric power $(\mathrm{kW})$ at time $t$ of the year $z . P_{E L}^{z}(t)$ refers to the power demand at time step $t$ of the year $z . N u m_{P V}, N u m_{W T}$, and Num $m_{M R}$ indicate the number of solar $\mathrm{PV}$, the number of wind turbine, and the number of MR, respectively. $P_{p v}(t), P_{w}(t)$, and $P_{M R}(t)$ refer to the power generation from solar PV, wind turbine, and MR at the time $t$, sequentially.

The power generation for Renewable and Fossil Fuel-based Hybrid Energy Systems (F-R HES), Standalone Nuclear Energy System, and Standalone Fossil Fuel-based Energy System can be formulated by the Equation (54), (55), and (56), respectively.

$$
\begin{array}{r}
\sum P_{\text {gen }}^{z}(t)=\sum_{t=1}^{t_{\text {total }}} N u m_{P V} P_{p v}(t)+\sum_{t=1}^{t_{\text {total }}} N u m_{W T} P_{w}(t)+\sum_{t=1}^{t_{\text {total }}} N u m_{D G} P_{D G}(t) \quad \forall t \in t_{\text {total }}, \forall z \\
\sum P_{\text {gen }}^{z}(t)=\sum_{t=1}^{t_{\text {total }}} N u m_{M R} P_{M R}(t) \quad \forall t \in t_{\text {total }}, \forall z \\
\sum P_{\text {gen }}^{z}(t)=\sum_{t=1}^{t_{\text {total }}} N u m_{D G} P_{D G}(t) \quad \forall t \in t_{\text {total }}, \forall z
\end{array}
$$

The energy storage device is used to store excess energy and supply energy during generation shortage. The following constraints are considered in this study to ensure the proper energy management of the system and maintain the desired SOC of the storage device.

$$
S O C_{E E S, \min } \leq S O C_{E E S}^{z}(t) \leq S O C_{E E S, \max } \quad \forall t \in t_{\text {total }}, \forall z
$$

where, $S O C_{E E S}^{z}(t)$ is the SOC (\%) of the energy storage device at the time step $t$ in the year z. $S O C_{E E S, \min }$ and $S O C_{E E S, \max }$ refer to the minimum and maximum $S O C$ of the energy storage component. This constraint will ensure that the usage of energy storage systems will be within the upper and lower limit which is important for the longevity of the energy storage systems (battery).

To ensure the reliability, resiliency, and performance of the energy system, the reliability parameter, LPSP, is considered as a constraint of the optimization problem. The LPSP is considered for each time step and also for the total time step to ensure the utmost reliability of the system. The lower value of the LPSP refers to the higher reliability of the system. The reliability constraints can be formulated as follows.

$$
\begin{gathered}
\operatorname{LPSP}_{e} \leq \operatorname{LPSP}_{e, \text { max }} \\
\operatorname{LPSP}_{e(t)} \leq \operatorname{LPSP}_{e(t), \text { max }}
\end{gathered}
$$

where, $L P S P_{e, \max }$ is the maximum limit of the LPSP for the total time step and $L P S P_{e(t), \max }$ represents the maximum limit of the LPSP in each time step. The maximum limit of $L P S P_{e}$ and $\operatorname{LPSP}_{e(t)}$ is considered as $8 \%$ in this study, which is a typically acceptable margin for HES [48].

To ensure the cargo-carrying capacity of the marine ship, the ratio between the total weight of the energy system and the total cargo-carrying capacity of the ship is inserted as one of the constraints in the optimization problem. This constraint can be formulated by the following equation.

$$
S Y S_{w r} \leq S Y S_{w r, m a x}
$$

where, $S Y S_{w r}$ is the ratio between the total weight of the energy system and the total cargocarrying capacity of the ship, and $S Y S_{w r, \max }$ is the maximum limit of the ratio. In this study, the $S Y S_{w r, \text { max }}$ is taken as 0.005 considering the weight of the current energy system that is being used in the ship to ensure that the proposed system will not reduce the load-carrying 
capacity of the marine vessel. The total weight of the components of the N-R HES, F-R HES, Standalone Nuclear Energy System, and Standalone Fossil Fuel-Based Energy System can be calculated by using the Equation (61), (62), (63), and (64), respectively.

$$
\begin{gathered}
S Y S_{w, N R}=T W_{M R}+T W_{P V}+T W_{\text {Wind }}+T W_{B A T} \\
S Y S_{w, F R}=T W_{D G}+T W_{P V}+T W_{\text {Wind }}+T W_{B A T} \\
S Y S_{w, N}=T W_{M R} \\
S Y S_{w, F}=T W_{D G}
\end{gathered}
$$

where, $T W_{M R}, T W_{P V}, T W_{W i n d}, T W_{D G}$, and $T W_{B A T}$ represent the total weight of the MR, solar PV, wind turbine, diesel generator, and battery, respectively. The weight of the MR, diesel generator, solar PV, wind turbine, and the battery can be formulated by the Equation (65), (66), (67), (68), and (69), respectively.

$$
\begin{aligned}
& T W_{M R}=N u m_{M R} \times P W R_{M R} \times R_{a t} M R \\
& T W_{D G}=N u m_{D G} \times P W R_{D G} \times R a t_{D G} \\
& T W_{P V}=N_{u m} \times P W R_{P V} \times \operatorname{Rat}_{P V} \\
& T W_{\text {Wind }}=\text { Num }_{\text {Wind }} \times P W R_{\text {Wind }} \times \text { Rat }_{\text {Wind }} \\
& T W_{B A T}=N u m_{B A T} \times P W R_{B A T} \times \operatorname{Rat}_{B A T}
\end{aligned}
$$

where, $P W R_{M R}, P W R_{D G}, P W R_{P V}, P W R_{W i n d}$, and $P W R_{B A T}$ refer to the power to weight ratio of MR, fossil fuel-based generator, solar PV, wind turbine, and battery, respectively. The Rat $M R$, Rat $_{D G}, \operatorname{Rat}_{P V}$, Rat $_{\text {Wind }}$, and Rat $_{B A T}$ refer to the rating of the MR, fossil fuelbased generator, solar PV, wind turbine, and battery, sequentially.

Unlike land-based system, marine ship has a limited area to accommodate the energy system components. To ensure that the system components can be accommodated with the available useable area of the ship, another constraint is addressed in the optimization problem. Solar PV is installed on the upper surface of the ship and requires a considerable amount of area compared to other energy sources [61]. Therefore, this constraint is used in the optimization problem to confirm that the solar PV can be implemented within the area of the ship. This constraint can be formulated as below.

$$
\text { Solar }_{\text {ratio }} \leq \text { Solar }_{\text {ratio, } \max }
$$

where, Solar ratio is the ratio between solar PV area and ship area, and Solar ratio,max is the maximum limit of the ratio between solar PV and ship area. The area of the solar PV can be calculated as follows.

$$
\operatorname{Area}_{P V}=\operatorname{Num}_{P V} \times U A_{P V} \times \operatorname{Rat}_{P V}
$$

where, Area $_{P V}$ is the area of the solar PV $\left(\mathrm{m}^{2}\right)$, and $U A_{P V}$ is the area requirement of solar PV for per unit power $\left(\mathrm{m}^{2} / \mathrm{kW}\right)$. The $U A_{P V}$ is considered as $4.952\left(\mathrm{~m}^{2} / \mathrm{kW}\right)$ in this study [62]. Considering the area requirement for wind turbine installation and all the area of the marine ship is not practically available for solar PV, the Solar ratio,max is considered as 0.4 which is within the reasonable margin [22].

\subsection{Decision Variables}

The target of this optimization problem is to identify the optimal configuration of the energy system by minimizing the NPC of the systems. Four different energy systems are optimized in this research and compared with each other to find out the most feasible energy system for the marine ship. The decision variables of this optimization problem are the number of the required MRs, fossil fuel-based generators, solar PV, wind turbine, and 
battery. These decision variables are used to identify the size of the MR, fossil fuel-based generator, solar PV, wind turbine, and battery. The decision variables can be expressed as follows.

$$
\begin{array}{lr}
0 \leq \text { Num }_{M R} \leq \text { Num }_{M R, \text { max }} & N_{P V} \in \mathbb{Z} \\
0 \leq \text { Num }_{D G} \leq \text { Num }_{D G, \text { max }} & N_{W T} \in \mathbb{Z} \\
0 \leq \text { Num }_{P V} \leq \text { Num }_{P V, \text { max }} & N_{M M R} \in \mathbb{Z} \\
0 \leq \text { Num }_{W T} \leq \text { Num }_{W T, \text { max }} & N_{\text {Htank }} \in \mathbb{Z} \\
0 \leq \text { Num }_{B A T} \leq \text { Num }_{B A T, \text { max }} & N_{\text {Htank }} \in \mathbb{Z}
\end{array}
$$

where, Num $_{M R, \text { max }}, N u m_{D G, \text { max }}, N u m_{P V, \text { max }}, N u m_{W T, \text { max }}$, and $N u m_{B A T, \text { max }}$ refer to the maximum number of MR, fossil fuel-based generator (Diesel Generator), solar PV, wind turbine, and battery, respectively.

\subsection{Implementation of Optimization Algorithm: Differential Evolution}

The differential evolution algorithm was first proposed by Kenneth Price and Rainer Store [63]. It is a popular optimization technique, which uses a population of individual solutions to solve multidimensional real-valued functions. The principle idea of the DE algorithm is to produce temporary individual best based on the individual differences within the population and then rebuild the population evolutionary. Because of its robustness, the suitability of different numerical optimization, and better global convergence, it has been used extensively in many problems like image classification, linear array, neural network, and monopoles antenna [64]. To overcome the low search ability and premature convergence of quantum inspired differential evolution (QDE), an enhanced MSIQDE algorithm was proposed in [65]. For solving Minimum Sum-of-Squares Clustering problem, Memetic Differential Evolution (MDE) was employed in [66]. The authors offered four algorithm variants that differ on the matching approach. They compared their method with HG-MEANS and found competitive performance based on numerical experiments. Sunita et al. employed DE with dynamic mutation technique to solve multi-objective optimization model of a microgrid consists of solar and wind energy. They found that the value of crossover probability does not affect the optimization result significantly. The authors concluded that for getting the best result, the crossover probability should be 0.5 [67]. To overcome the limitations of Harmony Search (HS) algorithm, an improved differential HS was employed in [68]. The authors used twenty-two benchmark functions to assess the performance of eight optimization algorithms. For setting the parameters of the optimization algorithms, they utilized the recommendations of several authors. They set the crossover probability and scaling factor of DE algorithm as 0.6 and 0.6. For solving the slow convergence speed, low solution efficiency, and lack of diversity of DE algorithm, Quantum Differential Evolution (QDE) was employed in [69]. The author set the value of parameters based on the literature review. They set the value of crossover probability and scaling factor for different DE algorithms ranging from 0.5 to 0.9 . However, to evaluate the impact of crossover probability and scaling factor on optimization result, Adaptive Differential Evolution (ADE) algorithm is employed which is discussed in Section 4.5. The differential evolution has four major stages that are initialization, mutation, recombination/crossover, and selection.

In the initialization stage, random solutions are generated within a boundary. Then, each solution undergoes mutation and recombination phases, and lastly, the best solution is selected. This process takes place until it meets any stopping criteria. The program needs to generate the initial solutions randomly within the minimum and maximum value of each variable. Any random solution that is generated in the initialization phase can be formulated as follows [63].

$$
S_{(N, d)}=S_{(\min , d)}+\operatorname{rand} \times\left[S_{(\max , d)}-S_{(\min , d)}\right]
$$


where, $N$ refers to the Nth solution to be optimized and $d$ represents the parameter variables to be optimized. $S_{(\min , d)}$ and $S_{(\max , d)}$ represent the minimum and maximum range of the $\mathrm{d}$ parameter variables. The rand is a random number between 0 and 1 .

In the mutation stage, the random solutions (target solutions) which are generated in the initialization stage are optimized by mutating the solution. This solution is called the donor solution. The new solution after the mutation phase can be formulated as follows [63].

$$
Z_{(N, d)}=S_{(r 1, d)}+F \times\left[S_{(r 2, d)}-S_{(r 3, d)}\right]
$$

where, $r 1, r 2$, and $r 3$ are random solutions selected from 1 to $\mathrm{N}_{\mathrm{p}}$, and these solutions are mutually exclusive. $F$ represents the scaling factor, which is between 0 and 2 . The target solution does not participate in the mutation phase. Hence, in the differential evolution, the minimum population size is four.

After the mutation phase, the solution undergoes a crossover/recombination phase to add diversity to the solution. The solution following the crossover phase is called the trial solution. In this phase, the trial solution can be obtained either from the target solution or the donor solution based on the following condition [63].

$$
T_{(N, d)}=\left\{\begin{array}{cc}
Z_{(N, d)} & \varphi \leq C_{p} \text { or } N=\lambda \\
S_{(N, d)} & \varphi>C_{p} \text { and } N \neq \lambda
\end{array} \quad \lambda \in d\right.
$$

where, $C_{p}$ is the crossover probability, and $\varphi$ is the random number between 0 and $1 . \lambda$ is a randomly selected variable location from $d$. The $N=\lambda$ condition ensures that at least one solution in the crossover phase is taken from the donor solution. After getting the trial solution, its' boundary needs to be checked. If the trial solution is greater than the maximum limit then the solution is bounded back to the maximum value, and if the trial solution is less than the minimum value then it is bounded back to the minimum value.

In the selection stage, the objective function values are computed for all the solutions. The better solution, between the target solution and the trial solution, is selected for the next iteration; this is called the greedy selection method. After completing all the iteration, the best objective function value is obtained, and the associated solution is the global optimal solution. Differential Evolution implementation steps are discussed in detail as follows.

Read the following input data of the proposed energy systems:

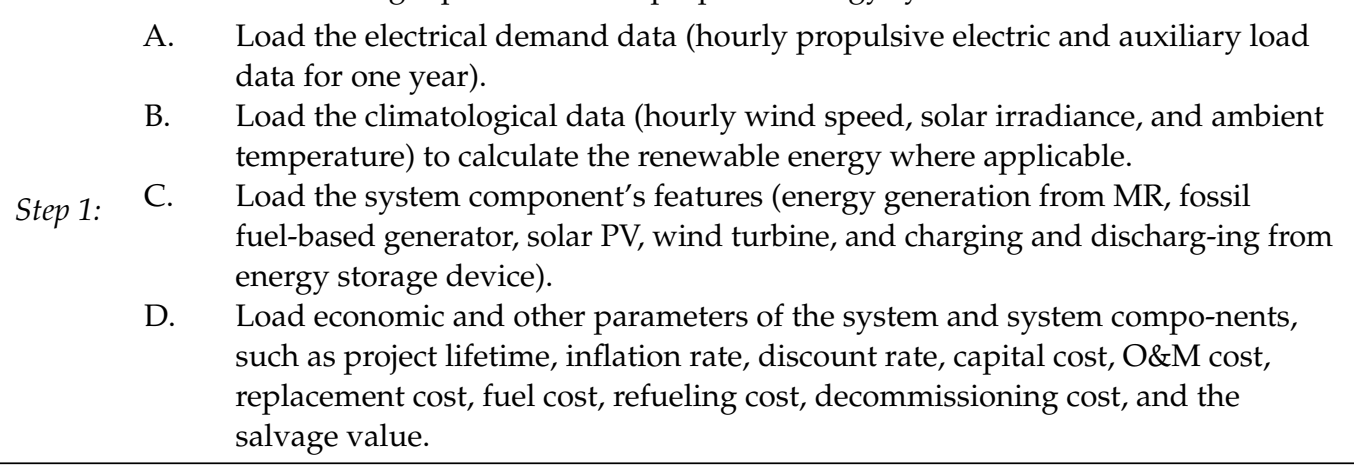

Initialize the parameters of $\mathrm{DE}$ and required system components:

Step 2: A. Set the population size, $N_{p}=50$, and the maximum number of iterations as 200 .

B. Set the scaling factor, $\mathrm{F}=0.5$

C. Set the crossover probability, $C_{p}=0.7$ 
D. Set the constraints of the optimization problem as follows.

$L P S P_{e} \leq 0.8 ; \operatorname{LPSP}_{e(t)} \leq 0.8 ; S Y S_{w} \leq 0.005 ;$ Solar $_{\text {ratio }} \leq 0.4$ A fixed value $\left(1 \times 10^{20}\right)$ will be added to the objective function if there is any violation in the constraints.

E. Set the lower and upper limit of the decision variables

- $\quad$ The lower and upper bound of the number of MR $[0,100]$.

- The lower and upper bound of the number of solar PV [0, 100].

- The lower and upper bound of the number of wind turbine $[0,100]$.

- The lower and upper bound of the number of battery [0, 100].

\begin{tabular}{|c|c|}
\hline Step 3: & $\begin{array}{l}\text { Generate the initial solutions randomly within the boundary of the decision variables. } \\
\text { The number of the randomly generated solution is equal to the population size. These } \\
\text { solutions are called target solutions. }\end{array}$ \\
\hline Step 4: & Generate the donor solutions by mutating the target solutions. \\
\hline Step 5: & Generate the trail solutions by recombing the donor the solutions (crossover). \\
\hline Step 6: & Bound the trial solutions within the boundary of the decision variables. \\
\hline Step 7: & $\begin{array}{l}\text { Evaluate the objective function for the target solutions and trial solutions. The solution } \\
\text { that gives the lower value (minimization problem) of the objective function is selected } \\
\text { as the target solution for the next iteration. Store the best cost value (lowest value) in } \\
\text { every iteration. }\end{array}$ \\
\hline Step 8: & $\begin{array}{l}\text { When the number of iteration reaches the maximum limit of the iteration, then stop. } \\
\text { Otherwise, continue from Step } 3 \text { to Step } 7 \text {. After completing all the iteration, the best } \\
\text { objective function value is obtained, and the associated solution is the global } \\
\text { optimal solution. }\end{array}$ \\
\hline
\end{tabular}

\subsection{Adaptive Differential Evolution}

Currently, the adjustment of control parameters (scaling factor and crossover probability) of DE is considered a global behavior. However, these parameters affect the convergence speed and may cause a premature phenomenon. An adaptive adjustment method of the control parameters was discussed in [64]. The authors used sine and cosine functions with a value of $(-1,0)$, and $(0,1)$, respectively. The scaling factor $(F)$ and the crossover probability $\left(C_{p}\right)$ can be written as follows [64].

$$
\begin{gathered}
F_{(t)}=\left\{\begin{array}{cc}
Y+(1-Y) \times \sin \left(\frac{\pi t}{\text { maxit }}-\frac{\pi}{2}\right) & t \leq \frac{\text { maxit }}{2} \\
Y-(1-Y) \times \cos \left(\frac{\pi}{2}-\frac{\pi t}{\text { maxit }}\right) & \text { otherwise }
\end{array}\right. \\
C_{p(t)}=\left\{\begin{array}{cc}
\beta+(1-\beta) \times \sin \left(\frac{\pi t}{\text { maxit }}-\frac{\pi}{2}\right) & t \leq \frac{\pi a x i t}{2} \\
\beta-(1-\beta) \times \cos \left(\frac{\pi}{2}-\frac{\pi t}{\text { maxit }}\right) & \text { otherwise }
\end{array}\right.
\end{gathered}
$$

where, $F_{(t)}$ is the scaling factor, $C_{p(t)}$ is the crossover probability, $t$ is the iteration number, and maxit is the maximum number of iterations. $Y$ and $\beta$ are constants, and the value of $Y$ and $\beta$ is 0.8 and 0.75 , respectively, in this study. This study compares the performance of standard DE and ADE, and evaluates the impact of control parameters of the DE algorithm on finding the optimized result.

\subsection{Implementation of Optimization Algorithm: Particle Swarm Optimization (PSO)}

The PSO is another metaheuristic optimization algorithm, proposed by Kennedy and Eberhart in 1995. The main idea of the PSO algorithm is communication among the population called the swarm and, evolutionary computation. In this technique, two values are compared in each position of a particle. The first value is the best value obtained by that particle so far, called the personal best and the 2nd value is the best value among all the particles, called the global best. The optimizer compares these two values for each particle and stores the best value till it reaches a stopping criteria (number of iterations or pre-defined value of the fitness function). Each particle moves towards the personal best 
and global best based on its current position and velocity. The position of a particle can be expressed as per the below equation [70].

$$
Z_{T+1}^{i}=Z_{T}^{i}+V_{T+1}^{i}
$$

where, $Z$ is the position of the particle, $i$ is the number of the particle, $V$ is the velocity of the particle, and $T$ is the number of iterations. The velocity of the particle can be obtained by the following equation [71].

$$
V_{T+1}^{i}=W\left[V_{T}^{i}+c_{1} r_{1}\left(p_{T}^{i}-Z_{T}^{i}\right)+c_{2} r_{2}\left(p_{T}^{g}-Z_{T}^{i}\right)\right]
$$

where, $W$ is the constriction coefficient, $p^{i}$ is the personal best position, $p^{g}$ is the global best position, $c_{1}$ is the acceleration coefficient (individual), $c_{2}$ is the acceleration coefficient (social), and $r_{1}$ and $r_{2}$ are random numbers between 0 and 1 . The constriction coefficient can be calculated as the following equation.

$$
\begin{gathered}
W=\frac{2 k}{\left|2-\varphi-\sqrt{\varphi^{2}-4 \varphi}\right|} \\
\varphi=c_{1}+c_{2}>4
\end{gathered}
$$

The typical value of $k, c_{1}$, and $c_{2}$ is $1,2.05$, and 2.05, respectively. The implementation steps of PSO are discussed below.

Read the following input data of the proposed energy systems:

A. Load the electrical demand data (hourly propulsive electric and auxiliary load data for one year).

B. Load the climatological data (hourly wind speed, solar irradiance, and ambient temperature) to calculate the renewable energy where applicable.

Step 1: C. Load the system component's features (energy generation from MR, fossil fuel-based generator, solar PV, wind turbine, and charging and discharging from energy storage device).

D. Load economic and other parameters of the system and system components, such as project lifetime, inflation rate, discount rate, capital cost, O\&M cost, replacement cost, fuel cost, refueling cost, decommissioning cost, and the salvage value.

Initialize the parameters of $\mathrm{DE}$ and required system components:

E. Set the population size, $\mathrm{N}_{\mathrm{p}}=50$, and the maximum number of iterations as 200 .

F. Set the acceleration coefficient, $c_{1}=c_{2}=2.05$

G. Calculate the value of the constriction coefficient, $W$.

H. Set the constraints of the optimization problem as follows: $L P S P_{e} \leq 0.8 ; \operatorname{LPSP}_{e(t)} \leq 0.8 ; S Y S_{w} \leq 0.005 ;$ Solar $_{\text {ratio }} \leq 0.4$ A fixed value

Step 2: $\quad\left(1 \times 10^{20}\right)$ will be added to the objective function if there is any violation in the constraints.

- $\quad$ Set the lower and upper limit of the decision variables.

- $\quad$ The lower and upper bound of the number of MR [0, 100].

- The lower and upper bound of the number of solar PV [0, 100].

- The lower and upper bound of the number of wind turbine $[0,100]$.

- The lower and upper bound of the number of battery [0, 100]. 


\begin{tabular}{ll}
\hline Step 3: & Generate the initial solutions randomly within the boundary of the decision variables. \\
\hline Step 4: & Use the individual particle position to determine the objective function value. \\
\hline Step 5: & $\begin{array}{l}\text { Update the best position of the individual particle by comparing it with all other } \\
\text { populations. }\end{array}$ \\
Step 6: & $\begin{array}{l}\text { Compare the personal best with the global best and update the global best with the } \\
\text { individual particle's personal best that has the minimum value of the } \\
\text { objective function. }\end{array}$ \\
Step 7: & Update the velocity of the individual particle. \\
\hline Step 8: & Update the position of the individual particle. \\
\hline Step 9: & $\begin{array}{l}\text { Repeat step } 3 \text { to step } 8 \text { till all particles are evaluated in each iteration. Store the best } \\
\text { cost value. }\end{array}$ \\
\hline Step 10: & Stop the simulation if it reaches the maximum number of iterations.
\end{tabular}

\section{Results}

The findings of this study are discussed in this section. Section 5.1 covers the comparison among the proposed energy systems in terms of technical, economic, and environmental KPIs. The performance of the DE algorithm is evaluated and validated in Section 5.2.

\subsection{Comparison among the Proposed Hybrid Energy Systems}

The Differential Evolution (DE) algorithm is used to determine the lowest Net Present Cost of the four energy systems proposed for marine transportation. The four energy systems are defined as

Case-01: Standalone Fossil Fuel-based Energy Systems, Case-2: Renewable and Fossil Fuel-based Energy Systems, Case-3: Standalone Nuclear Energy Systems, and Case-04: Nuclear Renewable Hybrid Energy Systems.

Case-04 shows the lowest NPC (532.11 million \$) among all the energy systems, while Case-01 has the highest NPC (877.61 million \$). After introducing renewable energy with fossil fuel in Case-02, the NPC (875.90 million \$) reduces around 1.7 million USD compared with Case-01. Case-03 exhibits lower NPC (538.05 million \$) than Case-01 and Case-02 but a little bit higher than Case-04. The LCOE of all four cases follows a similar trend of NPC. The NPC and LCOE of all four cases are shown in Figure 2.

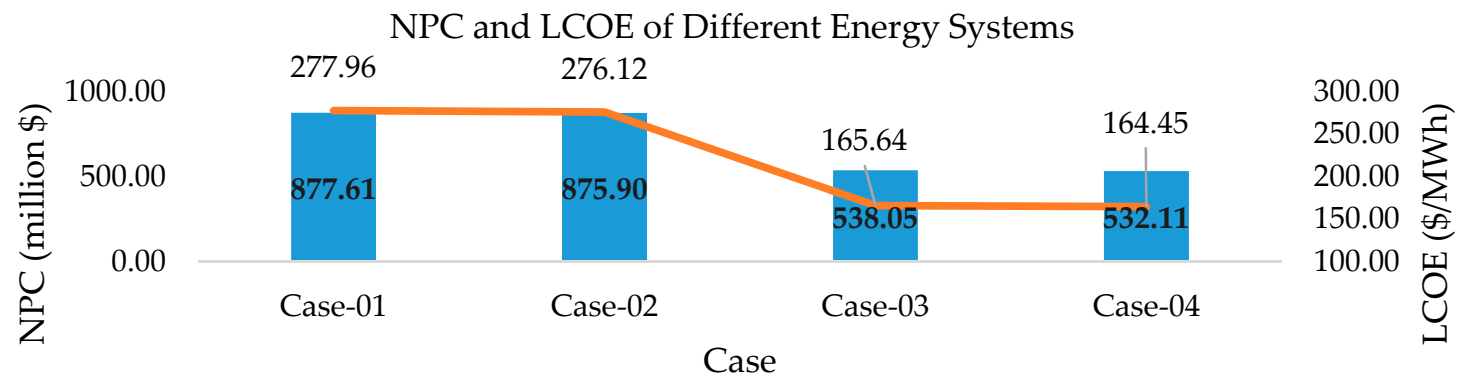

NPC (million \$) L LCOE (\$/MWh)

Figure 2. Comparison of NPC and LCOE of Different Energy Systems.

Table 1 shows the optimal rating of each component of all four energy systems. For all the energy systems, most of the energy is delivered by the diesel generator or MR based on the type of the energy system. The renewable energy penetration is higher in Case-04 compared to Case- 02 . The renewable energy penetration in Case- 04 is about $1.61 \%$ whereas the renewable energy penetration in Case- 02 is around $1.39 \%$. Case- 02 shows the highest dependency on the energy storage device, whereas Case- 03 exhibits the lowest dependency 
on the energy storage device for the optimal energy configuration. The ratings of the energy storage device for Case-01, Case-02, Case-03, and Case-04 are 2341.38 kWh, 3907.92 kWh, 637.17 kWh, and $1351.92 \mathrm{kWh}$, respectively. The Loss of Power Probability (LPSP) of all energy systems is within the defined range (less or equal to $8 \%$ ) that ensures the utmost reliability while optimizing the systems. The GRF is another reliability factor that ensures the system's reliability in terms of energy generation. For a reliable energy system, usually, the GRF should be at least 100\%. Among the four cases, Case-03 has the highest value of GRF (145.38\%), and Case-01 has the lowest GRF (141.31\%). The GRF of Case-04 is $144.82 \%$, which is very close to Case-03. Therefore, Case-04 performs better than the other three energy systems in the ship in terms of economic (NPC, LCOE) and reliability (LPSP, GRF) KPIs.

The $\mathrm{CO}_{2}$ emissions is an environmental KPI that determines the impact of energy systems on the environment. In terms of environmental aspects, Case-04 shows the least impact on the environment. Only 935.57 tons of $\mathrm{CO}_{2}$ is emitted from N-R HES whereas, $144,714.33$ tons of $\mathrm{CO}_{2}$ emits each year from Case-01. Hence, the proposed N-R HES will reduce around $99 \%$ of $\mathrm{CO}_{2}$ emissions compared to fossil fuel-based energy systems (Case-01). The penalty for emitting $\mathrm{CO}_{2}$ is the highest for Case-01 and the lowest for Case-04.

Table 1. Result of Optimization of Different Energy Systems.

\begin{tabular}{|c|c|c|c|c|}
\hline Parameter & Case-01 & Case-02 & Case-03 & Case-04 \\
\hline NPC $(\$)$ & $877,605,291.05$ & $875,903,862.16$ & $538,049,423.31$ & $532,112,182.13$ \\
\hline LCOE (\$/MWh) & 277.96 & 276.12 & 165.64 & 164.45 \\
\hline Generator/MMR (MW) & 28.15 & 28.14 & 28.96 & 28.00 \\
\hline Solar PV $(\mathrm{kW})$ & 0.00 & 396.79 & 0.00 & 0.0885334416 \\
\hline Wind $(\mathrm{kW})$ & 0.00 & 0.00 & 0.00 & 3050.30 \\
\hline Battery (kWh) & 2341.38 & 3907.92 & 637.17 & 1351.92 \\
\hline Solar ratio & $\mathrm{N} / \mathrm{A}$ & 0.10 & $\mathrm{~N} / \mathrm{A}$ & 0.000022 \\
\hline Energy System Weight (kg) & $1,546,864.99$ & $1,545,210.58$ & $445,816.43$ & $779,799.66$ \\
\hline LPSP & 0.080 & 0.079 & 0.080 & 0.08 \\
\hline CO2 Emissions (ton/year) & $144,714.33$ & $144,655.35$ & 967.73 & 935.57 \\
\hline Wratio & 0.005 & 0.005 & 0.001 & 0.0025 \\
\hline GRF & 141.31 & 141.98 & 145.38 & 144.82 \\
\hline Capital Cost $(\$)$ & $26,083,959.77$ & $25,882,395.10$ & $313,231,568.67$ & $308,562,984.45$ \\
\hline Replacement Cost (\$) & $131,028,335.96$ & $129,934,105.16$ & $651,048.07$ & $3,710,762.34$ \\
\hline $\begin{array}{c}\text { Operation and } \\
\text { Maintenance Cost }(\$)\end{array}$ & $16,414,843.54$ & $16,310,161.71$ & $154,912,891.56$ & $152,358,576.04$ \\
\hline Fuel Cost $(\$)$ & $637,771,484.30$ & $637,511,569.11$ & $32,482,148.04$ & $31,402,690.09$ \\
\hline Decommissioning Cost (\$) & $\mathrm{N} / \mathrm{A}$ & $\mathrm{N} / \mathrm{A}$ & $16,241,074.02$ & $15,701,345.05$ \\
\hline Refuel Cost $(\$)$ & $\mathrm{N} / \mathrm{A}$ & $\mathrm{N} / \mathrm{A}$ & $20,087,311.63$ & $20,087,311.63$ \\
\hline Carbon Penalty (\$) & $66,302,976.09$ & $66,275,955.20$ & $443,381.32$ & $428,646.72$ \\
\hline Salvage Value (\$) & 0.00 & $10,324.12$ & 0.00 & $140,134.20$ \\
\hline
\end{tabular}

The weight of the energy systems and $W_{\text {ratio }}$ (the ratio between the total weight of the energy system and the total cargo-carrying capacity of the ship) are two important factors that determine the cargo-carrying performance of the ship. The energy system weight for Case-03 and Case-04 are lower compared to Case-01 and Case-02. The energy system weight of Case-01, Case-02, Case-03, and Case-04 is 1,546,864.99 kg, 1,545,210.58 kg, $445,816.43 \mathrm{~kg}$, and $779,799.66 \mathrm{~kg}$, respectively. Compared to Case-01, the energy system weight of Case- 03 and Case- 04 is around 3 and 2 times lower, respectively. By using the proposed N-R HES in the ship, the ship operator will be able to carry 767 tons more cargo, which will increase the revenue of the ship. The lower value of $W_{\text {ratio }}$ is expected to carry more cargo by ship. The energy system weight and $W_{\text {ratio }}$ of four energy systems are presented in Figure 3. 
System Weight and Wratio of Different Energy Systems

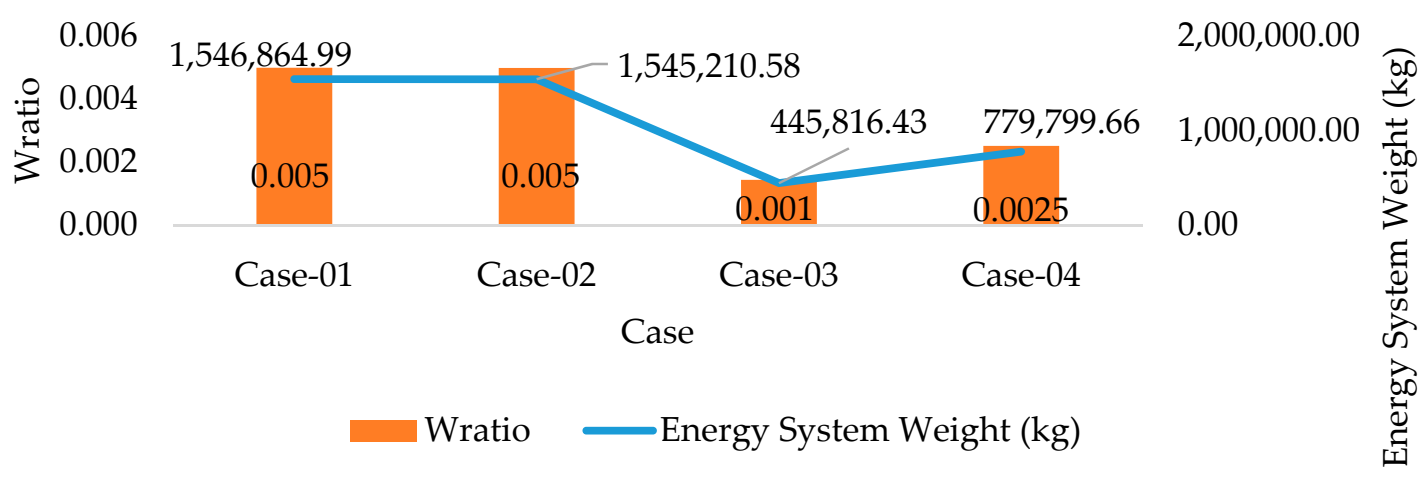

Figure 3. System Weight and $W_{\text {ratio }}$ of Different Energy Systems.

The cost distribution of different energy systems is shown in Figure 4. The capital cost of Case-01 and Case-02 is very low compared to Cae-03 and Case-04. Case-03 has the highest capital cost (313.23 million \$), and Case-02 has the lowest capital cost (25.88 million \$). After introducing renewable energy, the capital cost is reduced for Case-02 (25.88 million \$) compared to Case-01 (26.08 million \$). Also, for Case-03 the capital cost is 313.23 million \$ which is reduced to 308.56 million $\$$ after renewable energy addition in Case-04. The operation and maintenance cost follows the same trend as the capital cost. Case- 02 has the lowest O\&M cost (16.31 million \$), whereas Case-03 has the highest O\&M cost (154.91 million \$). The fuel cost shows that Case-01 and Case-02 have a higher cost associated with fuel compared to Case-03 and Case-04. Case-01 has the highest fuel cost (637.77 million \$) since the price of diesel fuel (per MWh) is much higher than nuclear fuel. After incorporating renewable energy in Case-02, the fuel cost (637.31 million \$) is reduced a little bit. With nuclear energy, the fuel cost is reduced to a great extent. The fuel cost of Case-03 is 32.48 million $\$$, and the fuel cost is reached the lowest value in Case-04 (31.40 million \$) by introducing renewable energy with nuclear energy. The replacement cost of Case- 01 is the maximum (131.03 million \$) among all the energy systems. The replacement cost reduced a bit in Case-02 (129.93 million \$). Unlike other costs, Case-04 has a higher replacement cost (3.71 million \$) compared to Case-03 (0.65 million \$). In Case-03, only battery replacement cost contributes to the total replacement cost, but replacement cost of renewable energy along with the battery replacement cost added to the total replacement cost in Case-04.

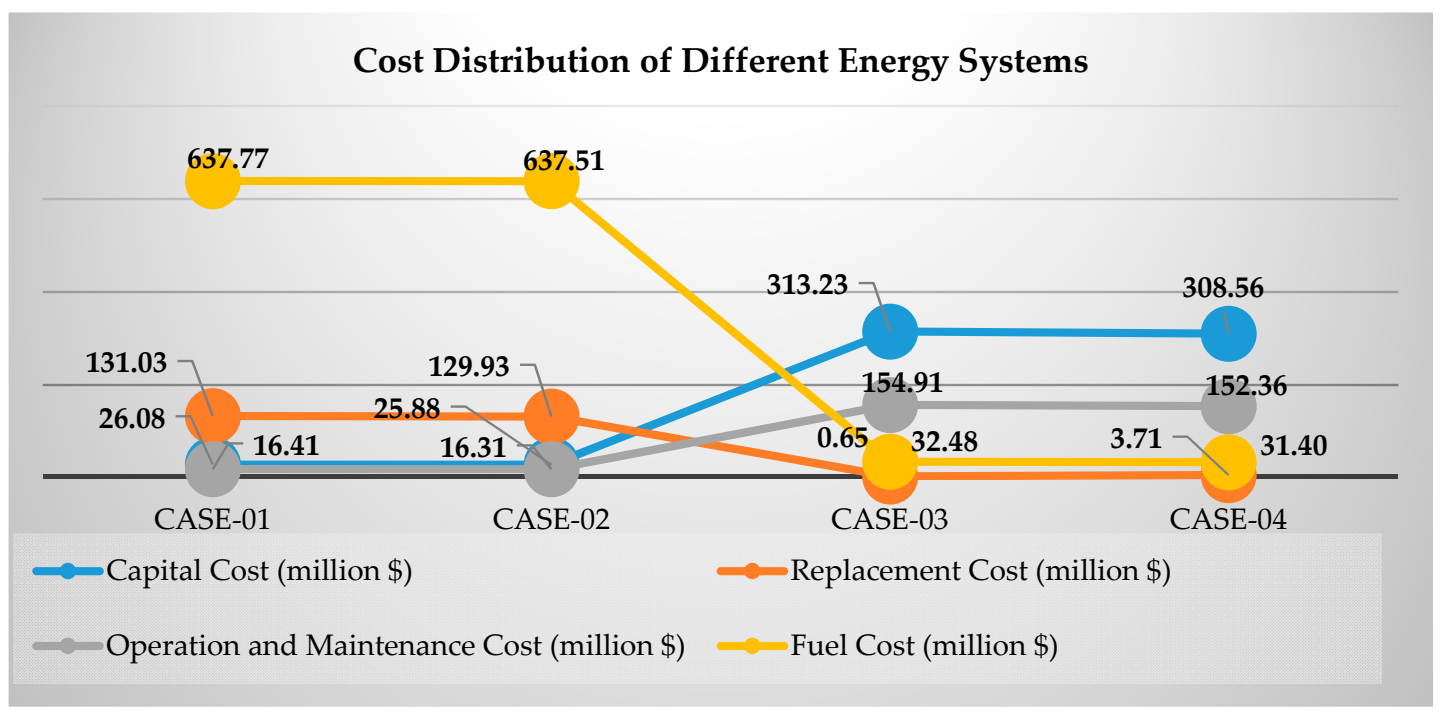

Figure 4. Cost Distribution of Different Energy Systems. 
Figure 5 shows the convergence plot for Case- 01 . The static penalty is added to the NPC till the 8th iteration. From the 9th iteration, the NPC is calculated without any penalty, and the optimization moves towards the minimum NPC. Figure 6 illustrates the cost breakdown of Case-01. More than two-thirds of the total cost of Case-01 is associated with the fuel cost $(72.67 \%)$, and the O\&M cost has the smallest portion $(1.87 \%)$. The replacement cost has the second-largest share (14.93\%) of the total cost. The capital cost is accounted for $2.97 \%$ of the cost while the carbon penalty made up $7.56 \%$ of the total cost.

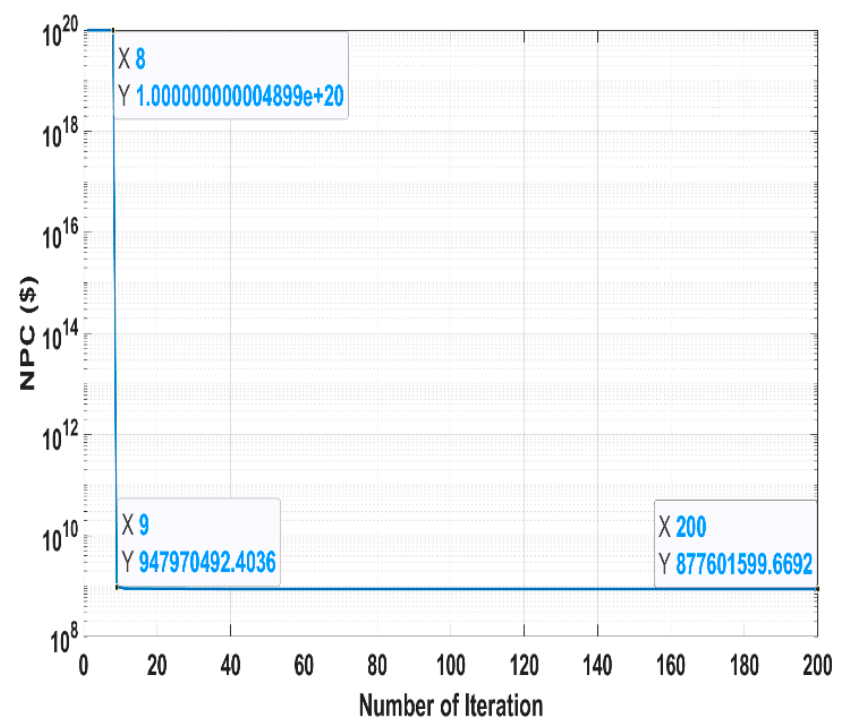

Figure 5. Convergence Plot (Case-01).

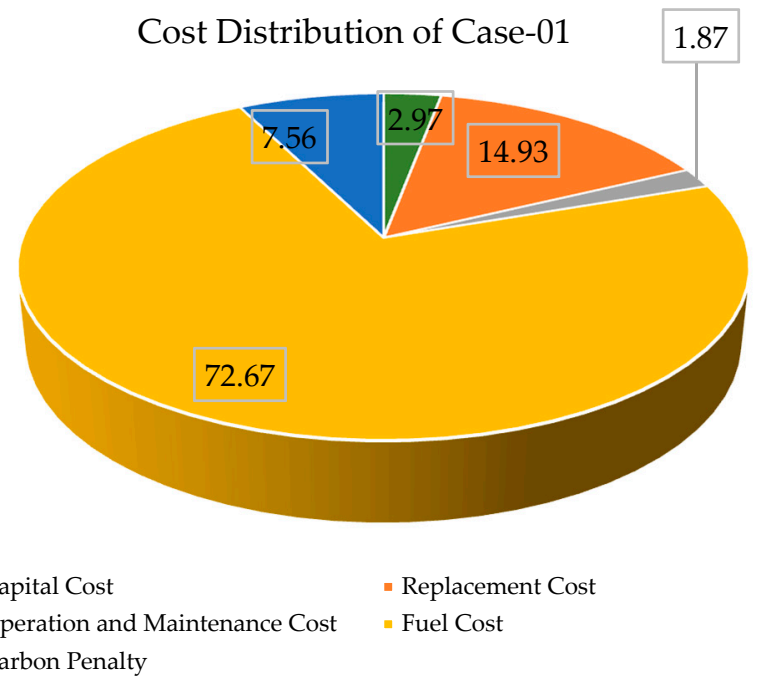

Figure 6. Cost Distribution (Case-01).

The convergence plot of Case- 02 is presented in Figure 7. The static penalty is added up to the 8th iteration and reaches the optimized value within the 200th iteration. The cost distribution for Case-02 is similar to Case-01 as shown in Figure 8. The fuel cost makes up the largest portion $(72.78 \%)$ of the total cost. The share of the replacement cost for Case- 02 $(14.83 \%)$ is a little bit lower compared to Case-01 (14.93\%). The capital cost and the O\&M cost comprise only $2.95 \%$ and $1.86 \%$, respectively, of the total cost. The $\mathrm{CO}_{2}$ emissions penalty contributes $7.57 \%$ of the total cost of Case- 02 . 


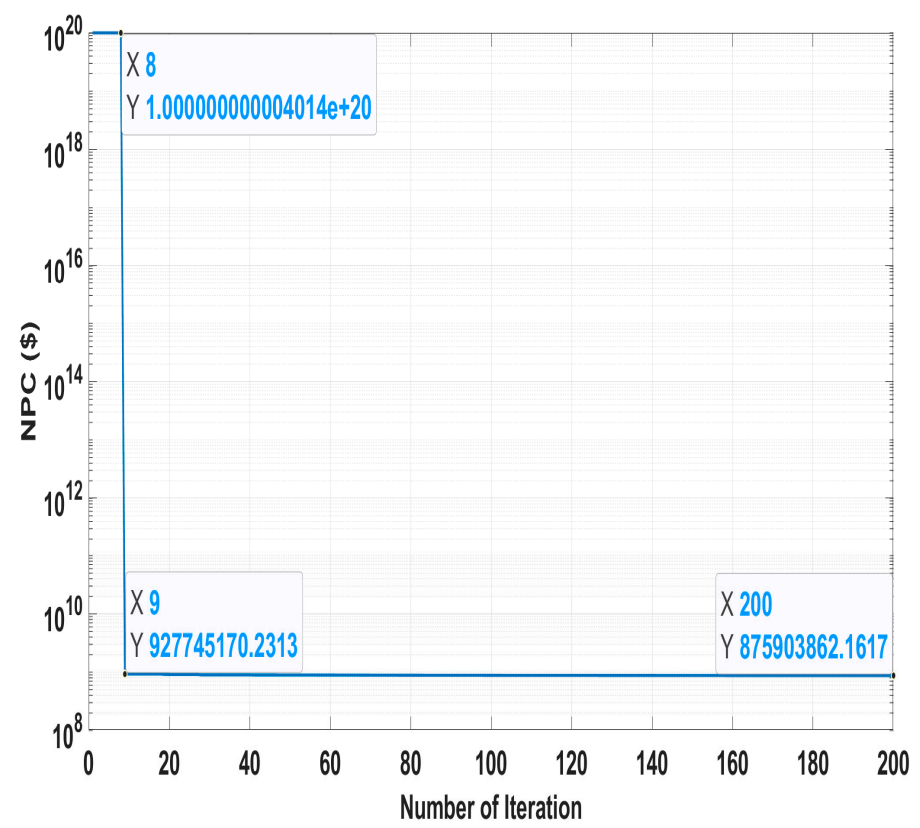

Figure 7. Convergence Plot (Case-02).

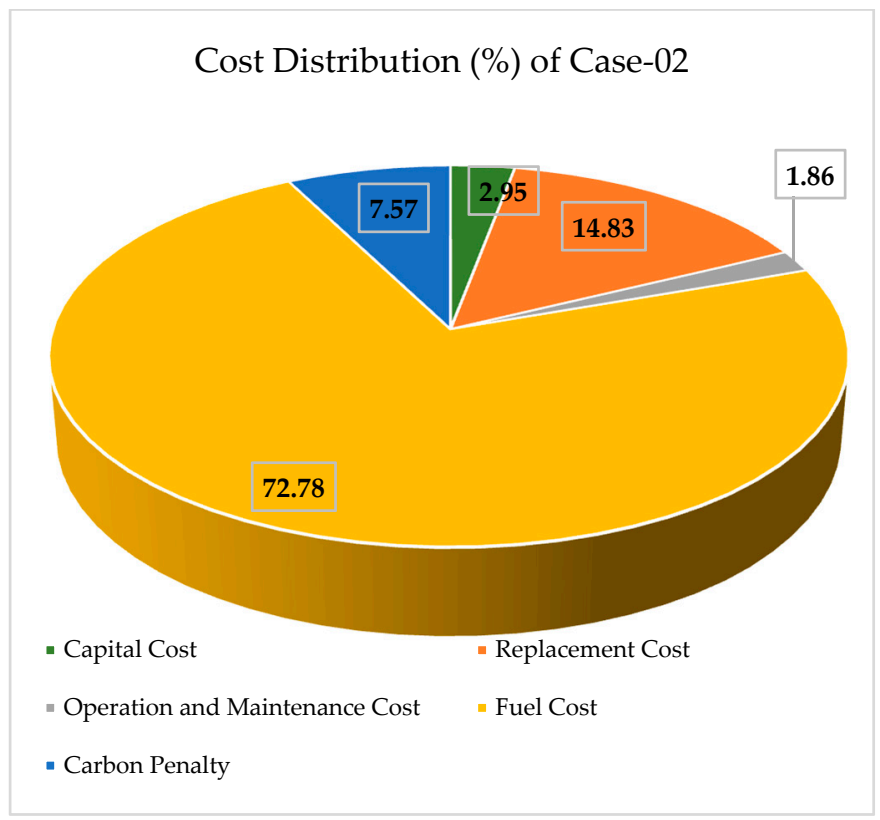

Figure 8. Cost Distribution (Case-2).

Figure 9 represents the convergence plot of Case-03. The algorithm finds the NPC without any static penalty from the 1st iteration. The algorithm moves to the optimal NPC range very quickly. The cost breakdown of Case-03 is shown in Figure 10. Unlike Case-01 and Case-02, the capital cost contributes more than half of the total cost (58.22\%). The O\&M cost makes up the second-largest $(28.79 \%)$ portion of the total cost. The fuel cost, refueling cost, and decommissioning cost comprise $6.04 \%, 3.73 \%$, and $3.02 \%$ cost, respectively. The shares of the replacement cost and the $\mathrm{CO}_{2}$ emissions penalty cost are very low (less than $1 \%$ ) for Case- 03. 


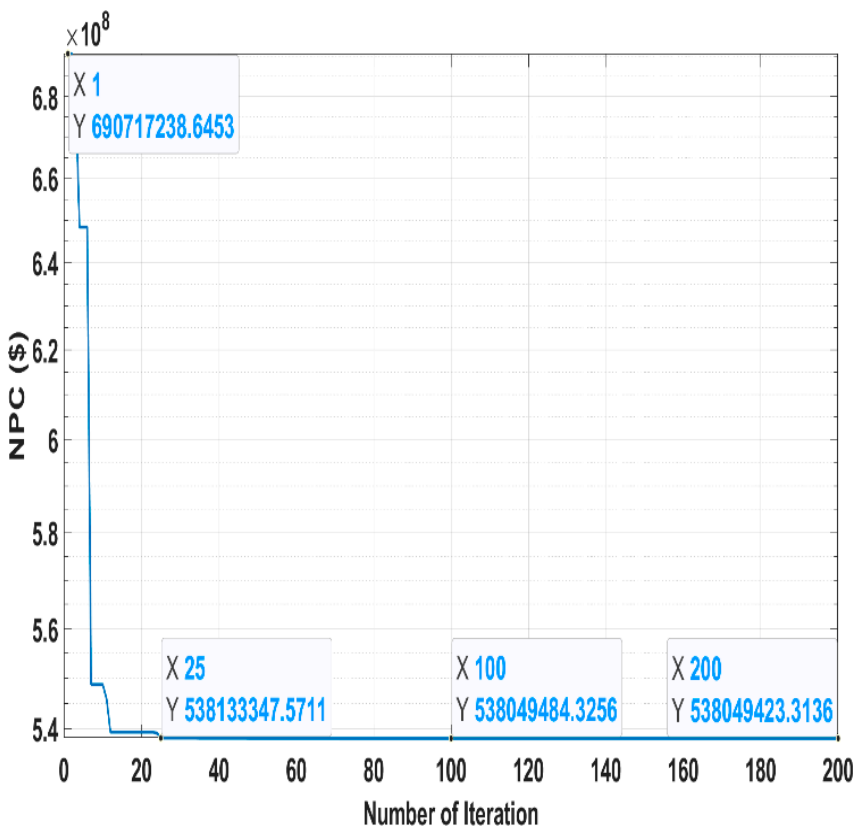

Figure 9. Convergence Plot (Case-03).

\section{Cost Distribution of Case-03}

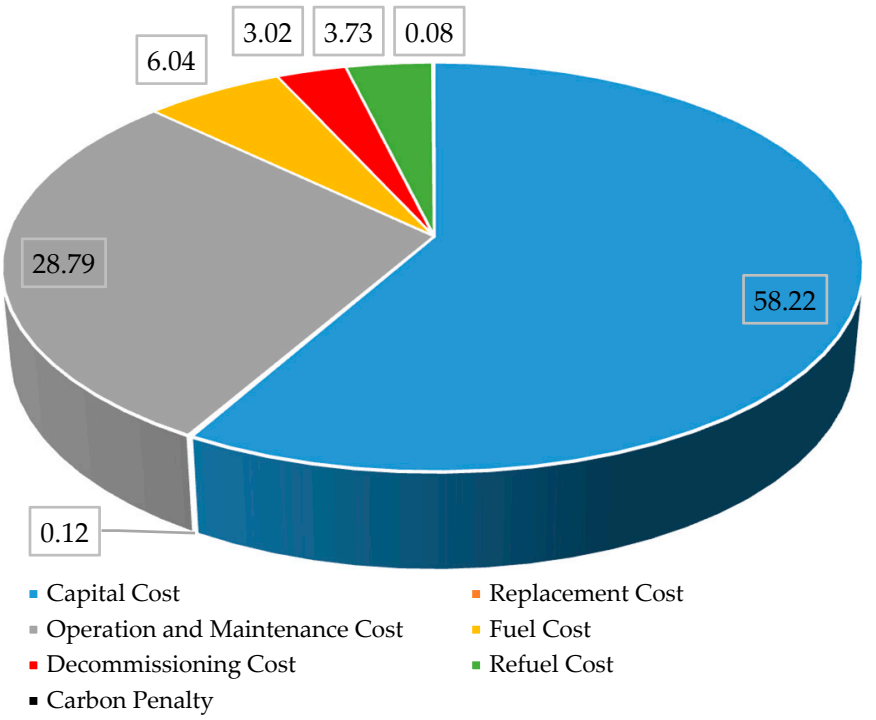

Figure 10. Cost Distribution (Case-03).

The convergence plot of Case-04 is presented in Figure 11. The cost distribution of Case-04 is illustrated in Figure 12. Like Case-03, the capital cost is accounted for more than half of the total cost (57.97\%). The O\&M cost comprises $28.63 \%$ of the cost. The fuel cost, decommissioning cost, and refueling cost make up $5.90 \%, 2.95 \%$, and $3.77 \%$, respectively, of the total cost. The replacement cost and the cost associated with $\mathrm{CO}_{2}$ emissions comprise only $0.70 \%$ and $0.08 \%$ cost, sequentially. 


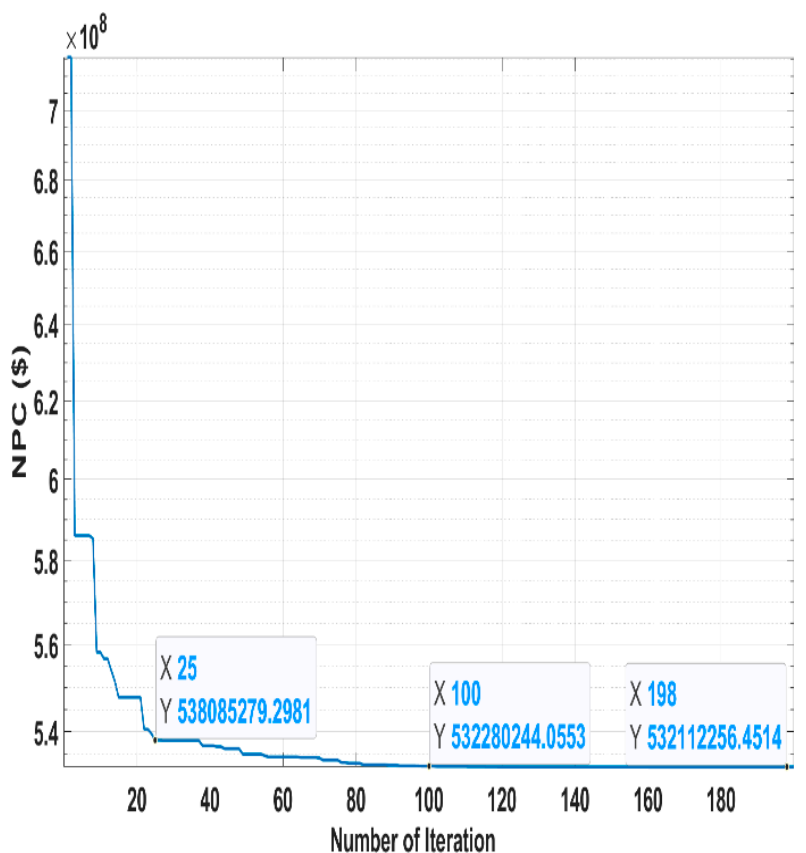

Figure 11. Convergence Plot (Case-04).

\section{Cost Breakdown of Case-04}

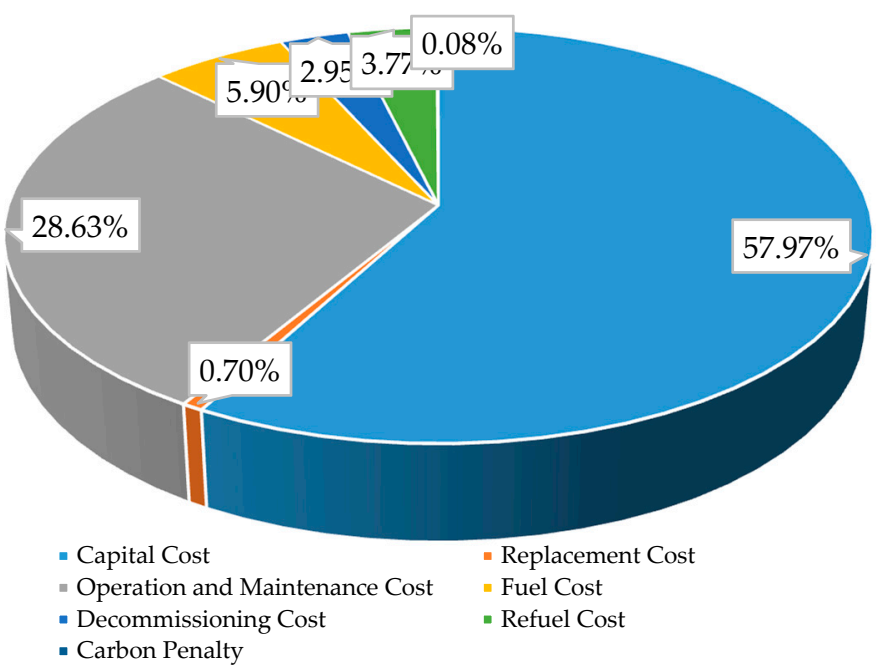

Figure 12. Cost Distribution (Case-04).

\subsection{Comparison and Validation of Optimization Techniques}

From the findings of Section 5.1, it is evident that Case-04 is best among all the four energy systems for marine transportation in terms of technical, economic, and environmental KPIs. The Differential Evolution (DE) optimization technique is used to optimize the systems. Hence, it is important to compare the findings of DE optimization with other widely used optimization techniques to validate and reinforce the results. In this section, the NPC of Nuclear-Renewable Hybrid Energy Systems (N-R HESs) obtained by DE are compared with PSO and ADE algorithm. Figure 13 shows the NPC of Case-04 for DE, ADE, and PSO. The lowest NPC $(\$ 532,112,182.13)$ is obtained by using the DE optimization technique although the NPC $(532,114,720.56)$ determined by the ADE is very close to DE. The difference between $\mathrm{DE}$ and $\mathrm{ADE}$ is only $0.0005 \%$. This suggests that the impact of the control parameters of DE optimization is very minimal on finding the lowest value 
of the objective function. Although the NPC $(\$ 532,118,322.71)$ determined by the PSO optimization is the highest among all the optimization techniques, the difference is very low $(0.0012 \%)$ compared to the DE optimization technique. This finding validates the result of the DE algorithm and suggests that the DE optimization technique performs better than ADE and PSO algorithm in this study.

Comparison of NPC Among Different Optimization Techniques

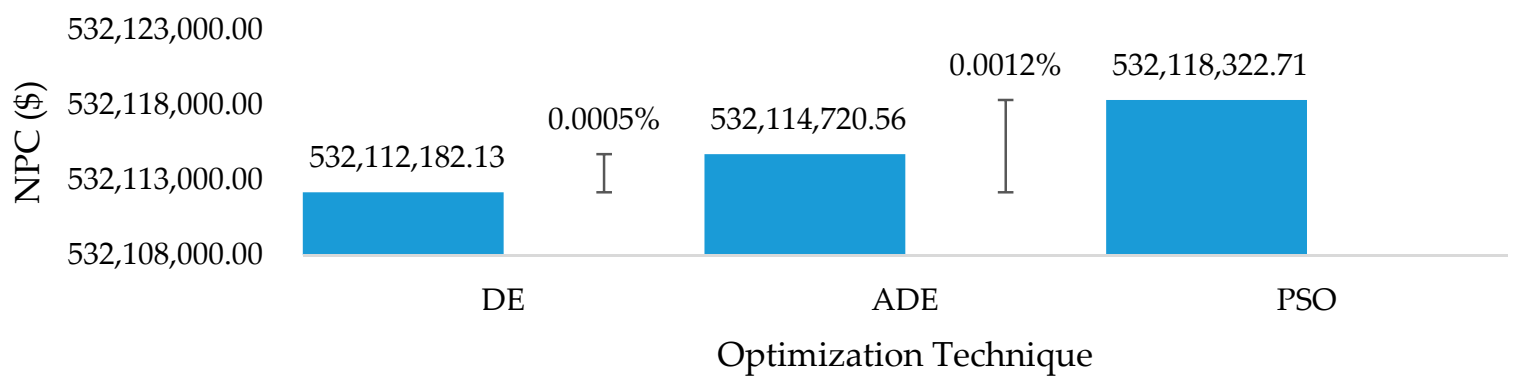

Figure 13. Comparison of NPC among Different Optimization Techniques.

\section{Sensitivity Analysis}

The N-R HES for marine transportation employs several economic, technical, and environmental variables, such as water temperature, water density, solar irradiance, wind speed, air temperature, discount rate, inflation rate, project lifetime, fuel cost, replacement cost, capital cost, operation and maintenance cost, $\mathrm{CO}_{2}$ penalty, $\mathrm{W}_{\text {ratio, }}$ and LPSP. Hence, a sensitivity analysis is crucial to assess the impact of these variables on the findings of the base model. The sensitivity analysis reinforces the results. The sensitivity analysis is also important to determine how sensitive the system to different parameters. The following subsections will assess the impact of different economic, technical, and environmental variables on the NPC of the four energy systems. The energy systems are optimized separately to get the optimized value of NPC for each parameter change in the sensitivity analysis.

\subsection{Sensitivity Assessment of Discount Rate on NPC}

In the base case, the discount rate is considered as $8 \%$. In the sensitivity analysis, the discount rate is varied from $5 \%$ to $10 \%$ to determine the impact on NPC. Figure 14 shows the NPC of the four energy systems for different discount rates varied from $5 \%$ to $10 \%$. From the figure, it can be observed that Case-04 always demonstrates the lowest NPC for the marine vessels irrespective of the discount rate. Also, the NPC of all the energy systems decreases with the increment of the discount rate.

\subsection{Sensitivity Assessment of Inflation Rate on NPC}

The inflation rate was considered $2 \%$ in the base case of the analysis. In the sensitivity analysis, the inflation rate is varied from $1 \%$ to $5 \%$ to identify the impact of the inflation rate on NPC of different energy systems. Figure 15 shows the NPC of different energy systems for different inflation rates. The NPC increases with the increase of the inflation rate with a varying range. However, Case-04 shows the lowest NPC among all the energy systems irrespective of the inflation rate.

\subsection{Sensitivity Assessment of Project Lifetime on NPC}

The project life is considered as 40 years in the base case analysis. The project lifetime can be different based on the requirement of the ship operator and lifetime of the ship. Hence, a sensitivity analysis is carried out for different project lifetimes. The project lifetime is varied from 20 years to 60 years with 10 years interval. The NPC of different energy systems for different project lifetimes is presented in Figure 16. The figure illustrates that with the increase of project lifetime NPC increases for all the cases. However, Case-04 shows the lowest NPC among all the energy systems irrespective of the project lifetime. 


\subsection{Sensitivity Assessment of Electrical Power Requirement on NPC}

This study employs several parameters, like seawater temperature, seawater density, length and width of the ship, average speed of the ship, and draught of the ship, to estimate the ship power. These parameters change with the position of the ship, weather, and type of the ship. Any change in these parameters will result in different electrical power requirements. Hence, it is important to assess the performance of the energy systems for different electrical power requirements. In this section, the electrical power of the ship is varied from $-20 \%$ to $+20 \%$ with $10 \%$ increment. Figure 17 shows the NPC of different energy systems with different electrical power. The figure tells that the NPC increases accordingly with the increase of electrical power. However, Case-04 illustrates the lowest NPC irrespective of the electrical power.

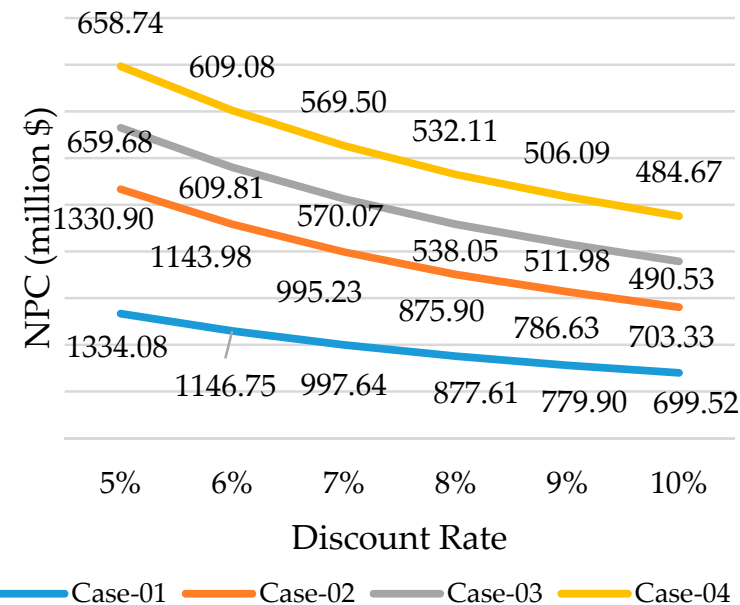

Figure 14. Sensitivity Assessment of Discount Rate on NPC.

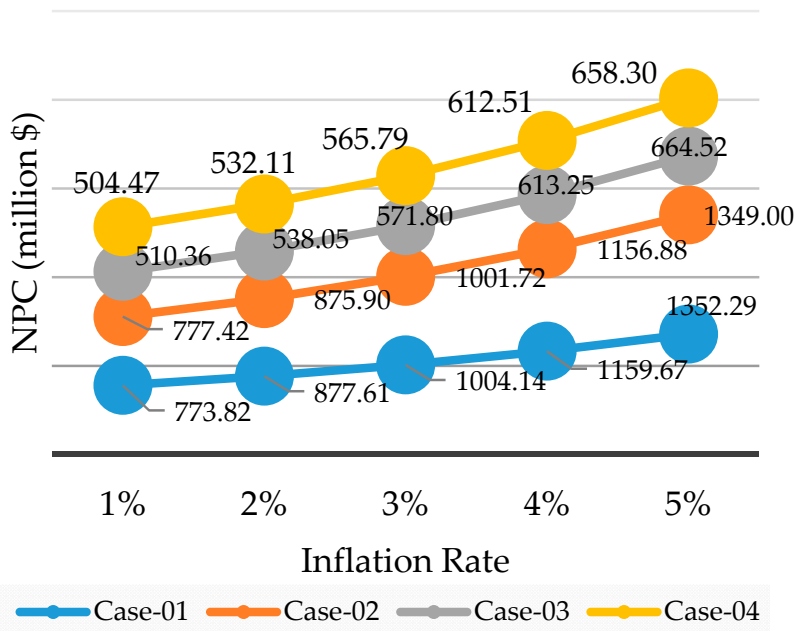

Figure 15. Sensitivity Assessment of Inflation Rate on NPC. 


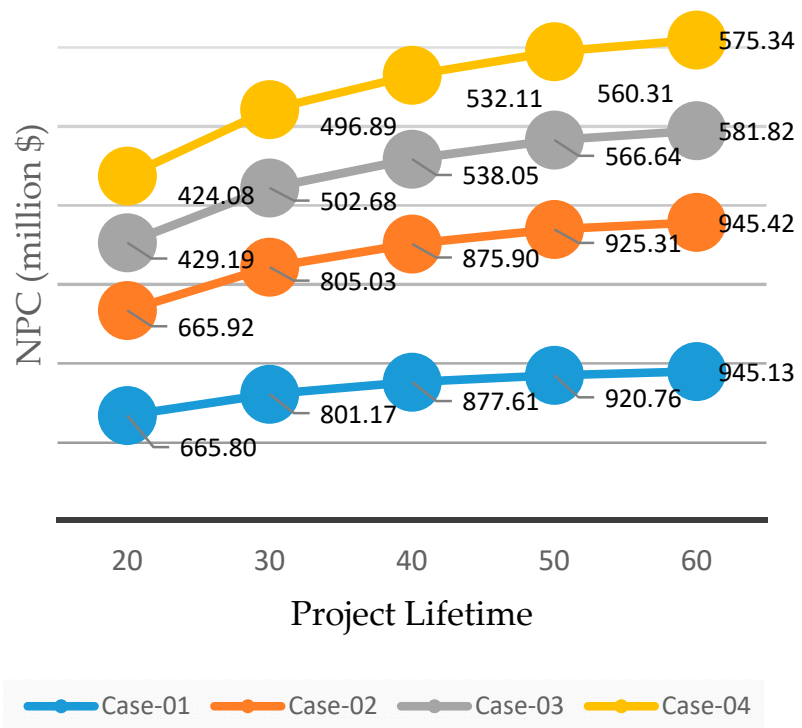

Figure 16. Sensitivity Assessment of Project Lifetime on NPC.

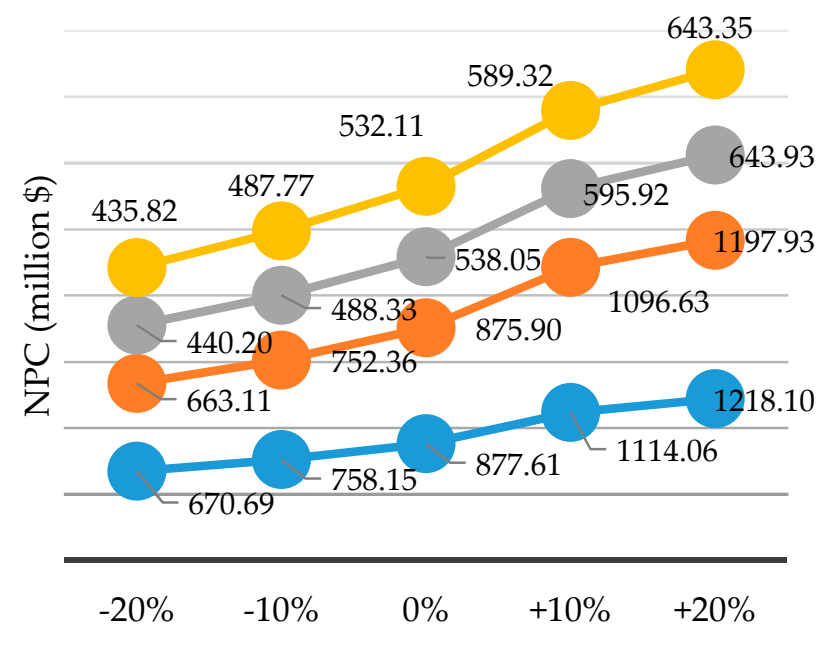

Rate of Change in Electrical Power

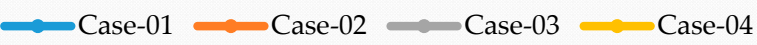

Figure 17. Sensitivity Assessment of Electrical Power Requirement on NPC.

\subsection{Sensitivity Assessment of Solar Irradiance on NPC}

In this study, the voyage route of the 'Baltic Sunrise' is considered from Iraq to Singapore. Renewable energy sources depend on the position of the ship, time, and direction. The solar irradiance will not be the same all the time, and the ship will not use the same route each time. Hence, a sensitivity assessment of solar irradiance is necessary to determine the impact on NPC. Since Case-01 and Case-03 do not have any solar PV, any change in the solar irradiance will not affect the NPC of these two cases. Hence, only Case02 and Case- 04 are considered for the assessment of solar irradiance on NPC. In this study, solar irradiance is varied from $-20 \%$ to $+20 \%$ with a $10 \%$ increment. Figure 18 shows the NPC of Case-02 and Case-04 for different solar irradiance. The NPC of Case-02 decreases slightly with the increase of solar irradiance while no impact on the NPC of Case-04 is observed with the change of solar irradiance. It should be noted that the penetration of 
solar PV in Case-04 is very minimal. However, Case-04 shows the lowest NPC among all the energy systems irrespective of the change in solar irradiance.

\subsection{Sensitivity Assessment of Wind Speed on NPC}

Like solar irradiance, wind speed also varies with the time and the route of the ship. Hence, a sensitivity assessment is carried out to identify the impact of wind speed on NPC on different energy systems. As there is no wind turbine for Casse-01 and Case-03, there is no impact with the change of wind speed on these cases. In this assessment, wind speed is varied from $-20 \%$ to $+20 \%$ with a $10 \%$ increment. Figure 19 shows the NPC of Case- 02 and Case-04 for different wind speeds. The NPC of Case-04 decreases with the increase of wind speed while no impact on the NPC of Case-02 is observed with the change of wind speed. However, Case-04 shows the lowest NPC among all the energy systems irrespective of the change in solar irradiance.

\section{Sensitivity Assessment of Solar Irradiance} on NPC

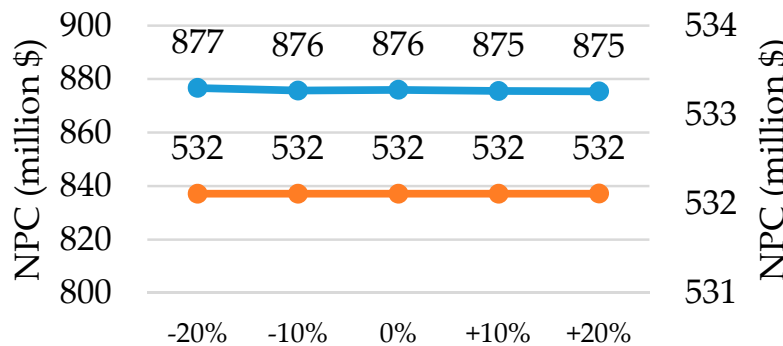

Change in Solar Irradiance

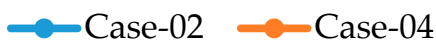

Figure 18. Sensitivity Assessment of Solar Irradiance on NPC.

\section{Sensitivity Assessment of Wind Speed on}

NPC
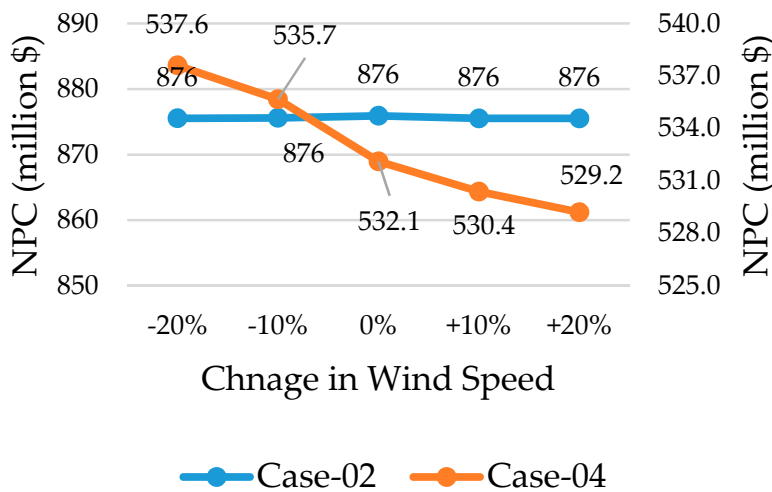

Figure 19. Sensitivity Assessment of Wind Speed on NPC.

\section{Conclusions, Contribution and Future Scope of Work}

Several studies have been conducted on stand-alone nuclear energy systems and fossil fuel-renewable hybrid energy systems for ocean-going marine ships to reduce GHG emissions. However, both systems have some limitations in terms of economic, regulatory, and technical points of view. Hence, a nuclear-renewable hybrid energy system on marine ships has been proposed in this paper to overcome these limitations. The energy demand of a ship is estimated by using actual data to simulate the real-world scenario. The mathemat- 
ical modeling and simulation are carried out in MATLAB environment by implementing a Differential Evolution (DE) algorithm. The findings of this paper suggest that an integrated nuclear-renewable hybrid energy system could be the best solution to make ocean-going ships free from emissions, and it is technically and economically feasible. Among the four energy systems, N-R HES shows the lowest NPC (532.11 million \$) compared to Standalone Fossil Fuel-based Energy System (877.61 million \$), Renewable Energy and Fossil Fuel-based Hybrid Energy System (875.90 million \$), and Stand-alone Nuclear Energy System (538.05 million \$). The proposed N-R HES emits the lowest $\mathrm{CO}_{2}$ gas compared to other energy systems in the entire project life. The study identifies the 'Capital Cost' and 'O\&M Cost' as the major contributors of NPC for Case-03 and Case-04, whereas 'Fuel Cost' and 'Replacement Cost' have the major contribution towards NPC for Case-01 and Case-02. This study also ensures the reliability of the proposed with adequate margins during the optimization of the systems. The research determines MRs as a competent candidate to replace the diesel generator from maritime transportation.

The optimized result of Case-04 obtained by the Differential Evolution (DE) algorithm is compared with PSO and ADE to validate the results. Among all the optimization techniques, DE performs better than the other two algorithms. The NPC (N-R HES) obtained by DE algorithm $(\$ 532,112,182)$ is the lowest compared to $\operatorname{ADE}(\$ 532,114,720)$, and PSO $(\$ 532,118,322)$. In the latter section, sensitivity analysis is carried out to reinforce the findings. The sensitivity assessment is conducted by varying the discount rate, inflation rate, project lifetime, electrical power requirement, solar irradiance, and wind speed. The sensitivity analysis shows NPC increases with the increase of inflation rate, project lifetime, and electrical power demand for energy systems. The NPC decreases with the increase of discount rate. The sensitivity analysis concludes Case-04 always shows the lowest NPC among all the energy systems irrespective of any change in the parameter.

The main contribution of this study is summarized below

$>$ A comprehensive literature review on the impact of maritime transportation on the environment, renewable and fossil fuel-based hybrid energy systems, nuclear propulsion, development of N-R HES in land-based applications to identify the problem and gaps.

$>$ Estimate the energy requirement of an oil tanker with the collaboration of industry (FleetMon) to address a real-world problem in this study.

$>$ Four energy systems are introduced to determine the most feasible energy system for maritime transportations. The feasibility is assessed based on technical, economical, and environmental KPIs. To ensure the reliability of the energy system, certain constraints are added.

$>$ The economical model of all the system components is developed mathematically. This mathematical model is then optimized in the popular and versatile simulator MATLAB. The Differential Evolution (DE) algorithm is used to optimize the energy systems.

$>$ The performance of the DE algorithm is compared to another optimization technique, PSO. Also, the impact of the control parameters of the DE algorithm is measured by the Adaptive Differential Algorithm (ADE).

$>$ To address the variability of the parameters like discount rate, inflation rate, project lifetime, electrical power requirements, solar irradiance, and wind speed, a sensitivity analysis is conducted to reinforce the findings.

The future scope of work is summarized below:

$>$ In this study, average solar irradiance, temperature, and wind speed are used while optimizing the systems. In the future, the actual solar irradiance, temperature, and wind speed can be used to make the study more realistic.

$>$ In this study, a specific ship route is considered. However, analysis can be extended to different major international shipping routes to assess the most feasible route for N-R HES. 
$>$ The safety of the N-R HES can be assessed in the future to check the feasibility in maritime transportation.

$>$ The licensing procedure and port approval of nuclear-powered merchant ships need to be addressed.

$>$ In this study, no secondary commodities are considered to utilize the excess heat of the nuclear reactor. In the future, the excess energy can be utilized to produce secondary commodities like seawater desalination or utilize it by using in heating and cooling system.

Author Contributions: Conceptualization, H.A.G., M.I.A., and M.R.A.; methodology, M.I.A. and H.A.G.; software, M.I.A.; validation, H.A.G., and M.I.A.; formal analysis, M.I.A. and H.A.G.; investigation, M.I.A.; resources, M.I.A.; data curation, M.I.A.; writing-original draft preparation M.I.A.; writing—review and editing, M.I.A.; visualization, M.I.A., and M.R.A.; supervision, H.A.G.; project administration, H.A.G.; funding acquisition, H.A.G. All authors have read and agreed to the published version of the manuscript.

Funding: This research was funded by Natural Sciences and Engineering Research Council of Canada, grant number 210320.

Institutional Review Board Statement: Not applicable.

Informed Consent Statement: Not applicable.

Data Availability Statement: Not applicable.

Conflicts of Interest: The authors declare no conflict of interest.

\section{Nomenclature}

$\begin{array}{ll}\text { AIS } & \text { Automatic Identification System } \\ \text { FFG } & \text { Fossil Fuel-based Generator } \\ \text { GHG } & \text { Greenhouse Gas } \\ \text { GRF } & \text { Generation Reliability Factor } \\ \text { HES } & \text { Hybrid Energy System } \\ \text { IAEA } & \text { International Atomic Energy Agency } \\ \text { KPI } & \text { Key Performance Indicator } \\ \text { LBP } & \text { Length Between Perpendiculars } \\ \text { MR } & \text { Microreactor } \\ \text { MT } & \text { Metric Ton } \\ \text { NASA } & \text { National Aeronautics and Space Administration } \\ \text { NPC } & \text { Net Present Cost } \\ \text { NPP } & \text { Nuclear Power Plant } \\ \text { NPV } & \text { Net Present Value } \\ \text { N-R HES } & \text { Nuclear-Renewable Hybrid Energy System } \\ \text { N-R HES } & \text { Nuclear-Renewable Hybrid Energy System } \\ \text { RES } & \text { Renewable Energy Source } \\ \text { RINA } & \text { Royal Institution of Naval Architects } \\ \text { SMR } & \text { Small Modular Reactor }\end{array}$

Appendix A

Table A1. Parameters and Assumptions of 'Baltic Sunrise'.

\begin{tabular}{ccccccc}
\hline SL. No & Parameter/Assumption & Category & Notation & Value & Reference \\
\hline 1 & Ship beam & Parameter & $B$ & $60 \mathrm{~m}$ & {$[72]$} \\
\hline 2 & Volume displacement & Parameter & $v$ & $344,649.08 \mathrm{~m}^{3}$ & {$[72]$} \\
\hline 3 & Draught & Parameter & $D$ & $21.6 \mathrm{~m}$ & {$[15]$} \\
\hline
\end{tabular}


Table A1. Cont.

\begin{tabular}{|c|c|c|c|c|c|}
\hline 4 & Extreme breadth (Beam) & Parameter & Bex & $60.04 \mathrm{~m}$ & [72] \\
\hline 5 & Average draught & Parameter & D_avg & $16.15 \mathrm{~m}$ & [15] \\
\hline 6 & Length between perpendiculars & Parameter & $L B P$ & $324 \mathrm{~m}$ & [72] \\
\hline 7 & Gravitational acceleration & Parameter & g & $9.81 \mathrm{~m} / \mathrm{s}^{2}$ & \\
\hline 8 & Seawater density at $30^{\circ} \mathrm{C}$ temperature & Parameter & $\rho_{w}$ & $1021.7 \mathrm{~kg} / \mathrm{m}^{3}$ & [17] \\
\hline 9 & Seawater viscosity at $30{ }^{\circ} \mathrm{C}$ temperature & Parameter & $\gamma_{w}$ & $0.84931 \times 10^{-6} \mathrm{~m}^{3} \mathrm{~s}^{-1}$ & [17] \\
\hline 10 & Average speed & Parameter & $V s \_a v g$ & $11.94 \mathrm{kn}$ or $6.1424 \mathrm{~ms}^{-1}$ & [15] \\
\hline 11 & $\begin{array}{c}\text { Incremental resistance coefficient due to } \\
\text { surface roughness of ship }\end{array}$ & Assumption & $\mathrm{C}_{\mathrm{A}}$ & 0.0004 & [17] \\
\hline 12 & Maximum speed & Parameter & $V s \_$max & $17.9 \mathrm{kn}$ or $9.2185 \mathrm{~ms}^{-1}$ & [15] \\
\hline
\end{tabular}

\section{Appendix B}

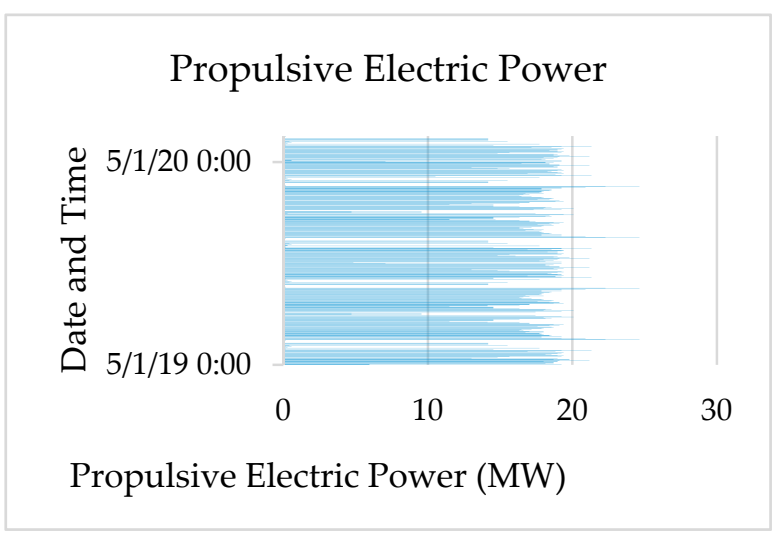

Figure A1. Ship Propulsive Power Requirement (Yearly).

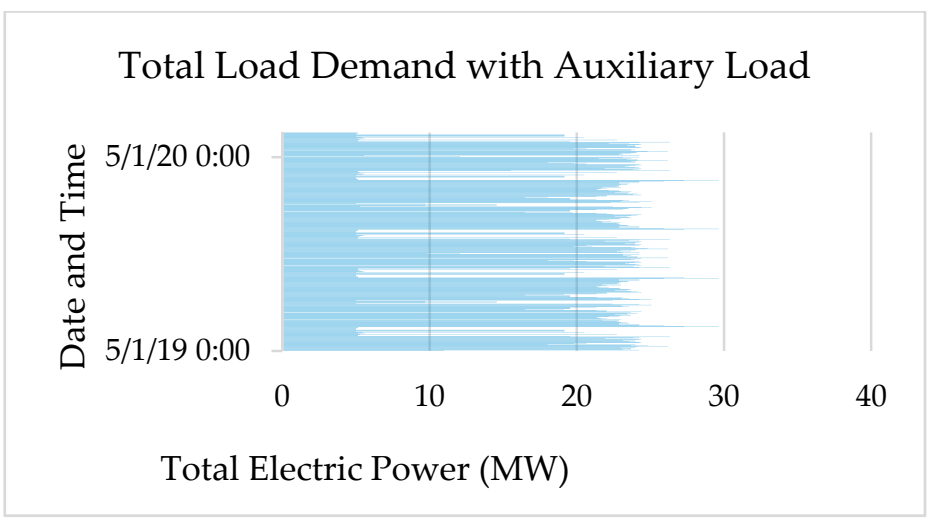

Figure A2. Ship Power Requirement (Yearly). 


\section{Appendix C}

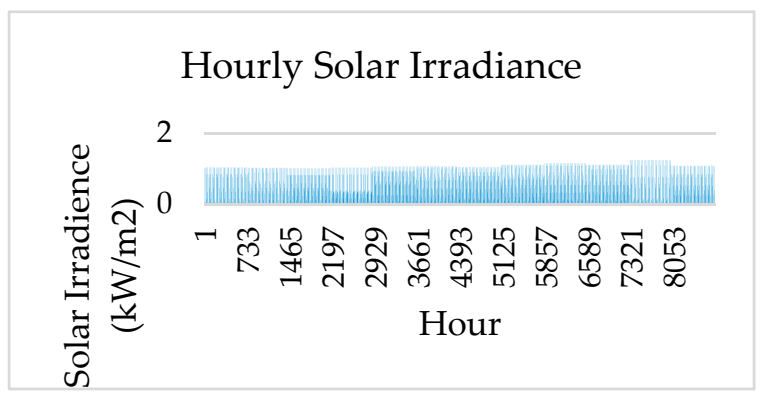

Figure A3. Hourly Solar Irradiance.

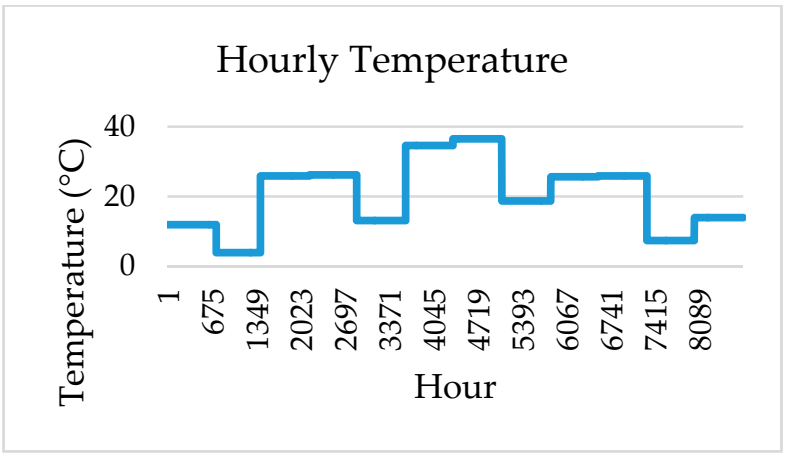

Figure A4. Hourly Temperature.

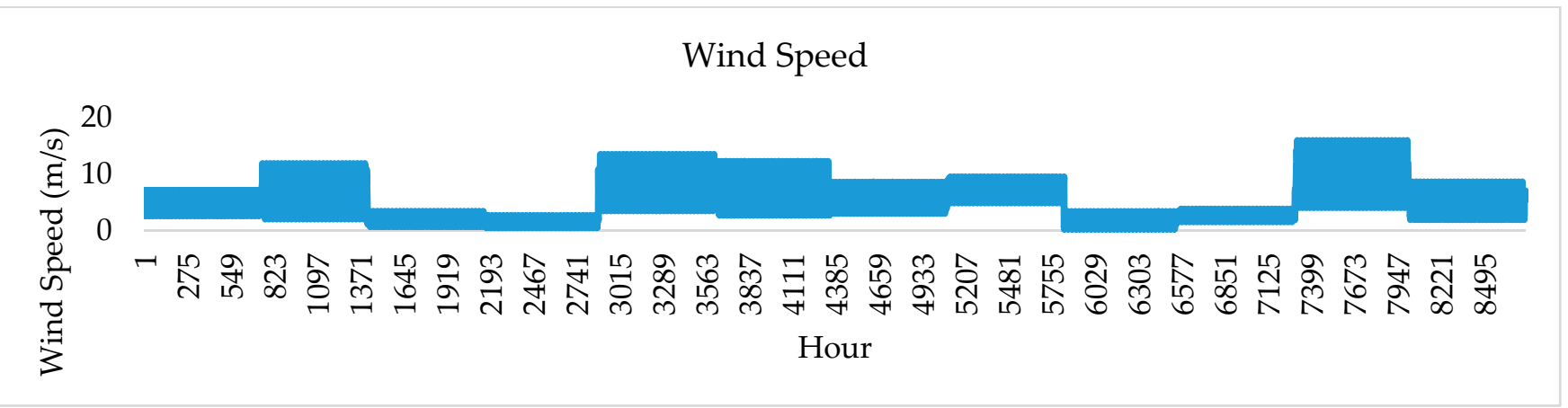

Figure A5. Hourly Wind Speed.

\section{Appendix D}

Table A2. PWR of Different Components of Energy Systems.

\begin{tabular}{ccccc}
\hline Component Name & Power $(\mathbf{k W})$ & Weight $\mathbf{( k g )}$ & PWR $\mathbf{( k W / k g )}$ & Reference \\
\hline MR/vSMR & 50,000 & 700,000 & 0.071 & {$[73]$} \\
Diesel Generator & 28,700 & 990,000 & 0.029 & {$[74]$} \\
Solar Panel & 375 & 21.591 & 0.05 & {$[75]$} \\
Wind Turbine & 1500 & 303,000 & 0.004 & {$[76]$} \\
Battery & 1600 & 48,000 & 0.03 & {$[5]$} \\
\hline
\end{tabular}

\section{References}

1. Shipping Pollution. OCEANA Protecting the World's Ocean. Available online: https://europe.oceana.org/en/shipping-pollution-1 (accessed on 17 October 2020). 
2. Yuan, J.; $\mathrm{Ng}$, S.H.; Sou, W.S. Uncertainty quantification of $\mathrm{CO}_{2}$ emission reduction for maritime shipping. Energy Policy 2016, 88 , 113-130. [CrossRef]

3. Koumentakos, A.G. Developments in Electric and Green Marine Ships. Appl. Syst. Innov. 2019, 2, 34. [CrossRef]

4. FUTURE SHIP POWERING OPTIONS Exploring Alternative Methods of Ship Propulsion. July 2013. Available online: https: / /www.raeng.org.uk/publications/reports/future-ship-powering-options (accessed on 12 April 2021).

5. Batteries on Board Ocean-Going Vessels. Available online: https://www.man-es.com/docs/default-source/marine/tools/ batteries-on-board-ocean-going-vessels.pdf?sfvrsn=deaa76b8_12 (accessed on 4 March 2021).

6. Borowski, P.F. Zonal and Nodal Models of Energy Market in European Union. Energies 2020, 13, 4182. [CrossRef]

7. Gravina, J.; Blake, J.I.R.; Shenoi, A.; Turnock, S.R.; Hirdaris, S.E. Concepts for a modular nuclear powered containership. In Proceedings of the 17th International Conference on Ships and Shipping Research (NAV 2012), Napoli, Italy, 17-19 October 2012.

8. Luciano Ondir Freire and Delvonei Alves de Andrade. Historic survey on nuclear merchant ships. Nucl. Eng. Des. 2015, 293, 176-186. [CrossRef]

9. Hirdaris, S.E.; Cheng, Y.F.; Shallcross, P.; Bonafoux, J.; Carlson, D.; Prince, B.; Sarris, G.A. Considerations on the potential use of Nuclear Small Modular Reactor (SMR) technology for merchant marine propulsion. Ocean Eng. 2014, 79, 101-130. [CrossRef]

10. Chaouki, G.; Maamar, B.; Boris, B.; Abdul, K.H. Hybrid solar PV/PEM fuel Cell/Diesel Generator power system for cruise ship: A case study in Stockholm, Sweden. Case Stud. Therm. Eng. 2019, 14, 100497. [CrossRef]

11. Diab, F.; Lan, H.; Ali, S. Novel comparison study between the hybrid renewable energy systems on land and on ship. Renew. Sustain. Energy Rev. 2016, 63, 452-463. [CrossRef]

12. Boldon, L.; Sabharwall, P.; Bragg-Sitton, S.; Abreu, N.; Liu, L. Nuclear Renewable Energy Integration: An Economic Case Study. Int. J. Energy Environ. Econ. 2015, 28, 85-95.

13. Gabbar, H.A.; Abdussami, M.R.; Adham, M.I. Micro Nuclear Reactors: Potential Replacements for Diesel Gensets within Micro Energy Grids. Energies 2020, 13, 5172. [CrossRef]

14. Gabbar, H.A.; Abdussami, M.R.; Adham, M.I. Optimal Planning of Nuclear-Renewable Micro-Hybrid Energy System by Particle Swarm Optimization. IEEE Access 2020, 8, 181049-181073. [CrossRef]

15. Voyage Analyser DEMO. Available online: https://voyage.vesselfinder.com/3a9abdd131b21a2a4f7d6acf52f0d2d2 (accessed on 17 October 2020).

16. Gabbar, H.A.; Adham, M.I.; Abdussami, M.R. Analysis of nuclear-renewable hybrid energy system for marine ships. Energy Rep. 2021, 7, 2398-2417. [CrossRef]

17. Chuku, A.J.; Ukeh, M.E.; Mkpa, A. Estimation of bare hull resistance of a ropax vessel using the ittc-57 method and gertler series data chart. Energy Rep. 2017, 3, 406-422.

18. Molland, A.F.; Turnock, S.R.; Hudson, D.A. Ship Resistance and Propulsion, Practical Estimation of Ship Propulsive Power; Cambridge University Press: Cambridge, UK, 2014; Chapter 10; p. 207.

19. Nicewicz, G.; Tarnapowicz, D. Assessment of Marine Auxiliary Engines Load Factor in Ports. Available online: https:// www.researchgate.net/publication/298026922_Assessment_of_marine_auxiliary_engines_load_factor_in_ports (accessed on 22 December 2020).

20. Moore, M. The Economics of Very Small Modular Reactors In The North. Canadian Nuclear Laboratories, Delta Ottawa City Centre Hotel CW-120200-CONF-012 Ottawa, Ontario, Canada, November 2016. Available online: https://inis.iaea.org/search/ search.aspx?orig_q=RN:49103606 (accessed on 25 December 2020).

21. Heydari, A.; Askarzadeh, A. Optimization of a biomass-based photovoltaic power plant for an off-grid application subject to loss of power supply probability concept. Appl. Energy 2016, 165, 601-611. [CrossRef]

22. Lan, H.; Wen, S.; Hong, Y.; Yu, D.C.; Zhang, L. Optimal sizing of hybrid PV/diesel/battery in ship power system. Appl. Energy 2015, 158, 26-34. [CrossRef]

23. Markvart, T. Solar Electricity; John Wiley \& Sons: Hoboken, NJ, USA, 2000.

24. Gabbar, H.A.; Abdussami, M.R.; Adham, M.I. Techno-Economic Evaluation of Interconnected Nuclear-Renewable Micro Hybrid Energy Systems with Combined Heat and Power. Energies 2020, 13, 1642. [CrossRef]

25. Solar Panel Maintenance Costs I Solar Power Maintenance Estimates. Fixr.com. Available online: https://www.fixr.com/costs/ solar-panel-maintenance (accessed on 16 April 2020).

26. What Is the Lifespan of a Solar Panel? Available online: https://www.engineering.com/DesignerEdge/DesignerEdgeArticles/ ArticleID/7475/What-Is-the-Lifespan-of-a-Solar-Panel.aspx (accessed on 16 April 2020).

27. SUN2000-(25KTL, 30KTL)-US, User Manual. HUAWEI TECHNOLOGIES CO., LTD. 1 April 2017. Available online: https: //www.huawei.com/minisite/solar/en-na/service/SUN2000-25KTL-30KTL-US/User_Manual.pdf (accessed on 29 May 2021).

28. Kobougias, I.; Tatakis, E.; Prousalidis, J. PV Systems Installed in Marine Vessels: Technologies and Specifications. Adv. Power Electron. 2013, 2013, 831560. [CrossRef]

29. Lu, L.; Yang, H.; Burnett, J. Investigation on wind power potential on Hong Kong islands—An analysis of wind power and wind turbine characteristics. Renew. Energy 2002, 27, 1-12. [CrossRef]

30. Borowy, B.S.; Salameh, Z.M. Methodology for optimally sizing the combination of a battery bank and PV array in a Wind/PV hybrid system. IEEE Trans. Energy Convers. 1996, 11. [CrossRef]

31. Yang, H.; Lu, L.; Zhou, W. A novel optimization sizing model for hybrid solar-wind power generation system. Sol. Energy 2007, 81, 76-84. [CrossRef] 
32. Yang, H.X.; Lu, L.; Burnett, J. Weather data and probability analysis of hybrid photovoltaic-wind power generation systems in Hong Kong. Renew. Energy 2003, 28, 1813-1824. [CrossRef]

33. Mukhtaruddin, R.N.S.R.; Rahman, H.A.; Hassan, M.Y.; Jamian, J.J. Optimal hybrid renewable energy design in autonomous system using Iterative-Pareto-Fuzzy technique. Int. J. Electr. Power Energy Syst. 2015, 64, 242-249. [CrossRef]

34. Bauer, L. Endurance E-3120 - 50.00 kW—Wind Turbine. Available online: https://en.wind-turbine-models.com/turbines/372endurance-e-3120 (accessed on 6 March 2021).

35. N. E. B. Government of Canada. NEB-Market Snapshot: The Cost to Install Wind and Solar Power in Canada is Projected to Significantly Fall Over the Long Term. 13 February 2020. Available online: https://www.cer-rec.gc.ca/nrg/ntgrtd/mrkt/snpsht/ 2018/11-03cstnstllwnd-eng.html (accessed on 24 July 2020).

36. US Wind O\&M Costs Estimated at $\$ 48,000 / \mathrm{MW}$; Falling Costs Create New Industrial Uses: IEA I New Energy Update. Available online: https: / / analysis.newenergyupdate.com/wind-energy-update/us-wind-om-costs-estimated-48000mw-falling-costscreate-new-industrial-uses-iea (accessed on 17 April 2020).

37. Stehly, T.; Beiter, P.; Heimiller, D.; Scott, G. 2017 Cost of Wind Energy Review. Renew. Energy 2018. [CrossRef]

38. Stackhouse, P.W. Surface Meteorology and Solar Energy (SSE) Data Release 5.1. Available online: https://ntrs.nasa.gov/search jsp?R=20080012141 (accessed on 24 July 2020).

39. Aeolos Wind Turbine Company-50kw Wind Turbine-Wind Power Generation-Aeolos 50 kw Turbine Wind Energy. Available online: https: / / www.windturbinestar.com/50kwh-aeolos-wind-turbine.html (accessed on 6 March 2021).

40. Diaf, S.; Notton, G.; Belhamel, M.; Haddadi, M.; Louche, A. Design and techno-economical optimization for hybrid PV/wind system under various meteorological conditions. Appl. Energy 2008, 85, 968-987. [CrossRef]

41. World Nuclear Association. Small Nuclear Power Reactors. Available online: https://www.world-nuclear.org/informationlibrary/nuclear-fuel-cycle/nuclear-power-reactors/small-nuclear-power-reactors.aspx (accessed on 25 December 2020).

42. Microreactors Frequently Asked Questions I Microreactors. Available online: https://inl.gov/trending-topic/microreactors / frequently-asked-questions-microreactors/ (accessed on 25 December 2020).

43. Cost Competitiveness of Micro-Reactors for Remote Markets. Available online: https://www.nei.org/resources/reports-briefs / cost-competitiveness-micro-reactors-remote-markets (accessed on 6 March 2021).

44. Borhanazad, H.; Mekhilef, S.; Ganapathy, V.G.; Modiri-Delshad, M.; Mirtaheri, A. Optimization of micro-grid system using MOPSO. Renew. Energy 2014, 71, 295-306. [CrossRef]

45. Marine Electrical Technology. Available online: https://www.goodreads.com/work/best_book/10132141-marine-electricaltechnology (accessed on 6 March 2021).

46. Ship's Emergency Power. DieselShipDieselShip, Connecting Mariners Worldwide. Available online: https://dieselship.com/marinetechnical-articles/marine-electro-technology/ships-emergency-power/ (accessed on 1 January 2021).

47. PV. Performance Modeling Collaborative. CEC Inverter Test Protocol. Available online: https://pvpmc.sandia.gov/modelingsteps/dc-to-ac-conversion/cec-inverter-test-protocol/ (accessed on 1 January 2021).

48. Luo, X.; Wang, J.; Dooner, M.; Clarke, J. Overview of current development in electrical energy storage technologies and the application potential in power system operation. Appl. Energy 2015, 511-536. [CrossRef]

49. Net Present Value (NPV). What is Net Present Value (NPV)? Available online: https:/ / corporatefinanceinstitute.com/resources / knowledge/valuation/net-present-value-npv/ (accessed on 3 January 2021).

50. Converting Nominal Interest Rates to Real Interest Rates I TVMCalcs.com. Available online: http://www.tvmcalcs.com/index. php/calculators/apps/converting_nominal_interest_rates_to_real_interest_rates (accessed on 11 May 2021).

51. Luna-Rubio, R.; Trejo-Perea, M.; Vargas-Vázquez, D.; Ríos-Moreno, G.J. Optimal sizing of renewable hybrids energy systems: A review of methodologies. Sol. Energy 2012, 86, 1077-1088. [CrossRef]

52. Oria, J.; Madariaga, E.; Ortega, A.; Díaz, E.; Mateo, M. Influence of characteristics of marine auxiliary power system in the energy efficiency design index. J. Marit. Transp. Eng. 2015, 4, 67.

53. Godsey, K.M. Life Cycle Assessment of Small Modular Reactors Using U.S. Nuclear Fuel Cycle. Clemson University. Available online: https: / core.ac.uk/download/pdf/287319878.pdf (accessed on 26 December 2020).

54. Parry, I. Countries Are Signing Up for Sizeable Carbon Prices. Available online: https://blogs.imf.org/2016/04/21/countriesare-signing-up-for-sizeable-carbon-prices/\#more-12399 (accessed on 6 January 2021).

55. IMF Calls for Carbon Tax on Ships and Planes. Available online: https://www.theguardian.com/environment/2016/jan/13 /imf-calls-for-carbon-tax-on-ships-and-planes (accessed on 17 October 2020).

56. Marine Insights. 14 Terminologies Used for Power of the Ship's Marine Propulsion Engine. Available online: https://www. marineinsight.com/main-engine/12-terminologies-used-for-power-of-the-ships-marine-propulsion-engine/ (accessed on 7 January 2021).

57. FANDOM. Power-to-Weight Ratio. Available online: https://automobile.fandom.com/wiki/Power-to-weight_ratio (accessed on 7 January 2021).

58. Salvage Value. Available online: https://www.homerenergy.com/products/pro/docs/latest/salvage_value.html (accessed on 13 July 2020).

59. Rubin, E.S.; Azevedo, I.M.L.; Jaramillo, P.; Yeh, S. A review of learning rates for electricity supply technologies. Energy Policy 2015, 86, 198-218. [CrossRef] 
60. Abdelshafy, A.M.; Hassan, H.; Mohamed, A.M.; El-Saady, G.; Ookawara, S. Optimal grid connected hybrid energy system for Egyptian residential area. In Proceedings of the 2017 International Conference on Sustainable Energy Engineering and Application (ICSEEA), Jakarta, Indonesia, 23-26 October 2017; pp. 52-60. [CrossRef]

61. NEI. Land Needs for Wind, Solar Dwarf Nuclear Plant's Footprint. Available online: https://www.nei.org/news/2015/landneeds-for-wind-solar-dwarf-nuclear-plants\#: \{\}:text=A\%20nuclear\%20energy $\% 20$ facility $\% 20$ has, $1 \% 2 \mathrm{C} 000 \% 20 \mathrm{megawatts} \% 20$ of $\% 20$ installed $\% 20$ capacity.\&text=A\%20solar\%20PV\%20facility \%20must,45\%20and \%2075\%20square\%20miles (accessed on 13 January 2021).

62. Solar Panel Size Guide: How Big Is a Solar Panel? Available online: https:/ /www.wholesalesolar.com/blog/solar-panel-sizeguide (accessed on 3 May 2021).

63. Greco, R.; Vanzi, I. New few parameters differential evolution algorithm with application to structural identification. J. Traffic Transp. Eng. 2019, 6, 1-14. [CrossRef]

64. Huang, Z.; Chen, Y. An Improved Differential Evolution Algorithm Based on Adaptive Parameter. J. Control Sci. Eng. 2013, 2013, 462706. Available online: https:/ /www.hindawi.com/journals/jcse/2013/462706/ (accessed on 1 March 2021). [CrossRef]

65. Deng, W.; Xu, J.; Gao, X.-Z.; Zhao, H. An Enhanced MSIQDE Algorithm With Novel Multiple Strategies for Global Optimization Problems. IEEE Trans. Syst. Man Cybern. Syst. 2020, 1-10. [CrossRef]

66. Mansueto, P.; Schoen, F. Memetic differential evolution methods for clustering problems. Pattern Recognit. 2021, 114, 107849. [CrossRef]

67. Shukla, S.; Pandit, M. Multi-objective fuzzy rank based scheduling of utility connected microgrid with high renewable energy using differential evolution with dynamic mutation. Int. Trans. Electr. Energy Syst. 2021, 31, e12787. [CrossRef]

68. Wang, L.; Hu, H.; Liu, R.; Zhou, X. An improved differential harmony search algorithm for function optimization problems. Soft Comput. 2019, 23, 4827-4852. [CrossRef]

69. Deng, W. Quantum differential evolution with cooperative coevolution framework and hybrid mutation strategy for large scale optimization. Knowl. Based Syst. 2021, 224, 107080. [CrossRef]

70. Rini, D.P.; Shamsuddin, S.M. Particle Swarm Optimization: Technique, System and Challenges. IJAIS 2011, 1, 33-45. [CrossRef]

71. Pranava, G.; Prasad, P.V. Constriction Coefficient Particle Swarm Optimization for Economic Load Dispatch with valve point loading effects. In Proceedings of the 2013 International Conference on Power, Energy and Control (ICPEC), Dindigul, India, 6-8 February 2013; pp. 350-354. [CrossRef]

72. Auke Visser's International Super Tankers. Available online: http:/ / www.aukevisser.nl/supertankers/VLCC\%20T-V/id1147. htm (accessed on 17 October 2020).

73. Maisler, J. Small Modular Reactors. Available online: http://hpschapters.org/florida/6spring.pdf (accessed on 7 January 2021).

74. RTA84T. Available online: https://pdf.nauticexpo.com/pdf/waertsilae-corporation/rta84t/24872-12529.html\#https://img. nauticexpo.com/pdf/repository_ne/24872/rta84t-12529_1b.jpg (accessed on 16 October 2020).

75. Canadian Solar CS6U-335P Silver Poly Solar Panel. Available online: https:/ /www.wholesalesolar.com/1930010/canadiansolar/solar-panels / canadian-solar-cs6u-335p-silver-poly-solar-panel (accessed on 16 October 2020).

76. National Wind Watch. Available online: https://www.wind-watch.org/faq-size.php (accessed on 16 October 2020). 